\title{
On the Evolution of Primary Gamma Prime Precipitates During High Temperature and High Strain Rate Deformation and Subsequent Heat Treatment in the Ni-Based Superalloy, RR1000
}

\begin{abstract}
N. D'SOUZA, W. LI, C. ARGYRAKIS, G.D. WEST, and C.D. SLATER
The microstructural evolution following compression and subsequent sub-solvus and supersolvus heat treatment was studied in the Ni-based superalloy, RR1000, typically used for rotor disc applications in aero-engines. For a low strain rate of $0.1 \mathrm{~s}^{-1}$ at close to solvus temperature, $1413 \mathrm{~K}\left(1140{ }^{\circ} \mathrm{C}\right)$, the flow stress is constant. For larger strain rates of 1 and $10 \mathrm{~s}^{-1}$ at sub-solvus temperature, $1373 \mathrm{~K}\left(1100{ }^{\circ} \mathrm{C}\right)$ dynamic re-crystallization (DRX) of $\gamma$ grains occurs during forging with accompanying stress decay. Incoherent primary $\gamma^{\prime}$ precipitates form mainly via meta-dynamic re-crystallization (MDRX) at $1 \mathrm{~s}^{-1}$ and are as intergranular. For $10 \mathrm{~s}^{-1}$, the coherently nucleated or existing precipitates present in the initial as-HIP condition become incoherent when the grain boundary sweeps past them during DRX and subsequent grain growth. The incoherent primary $\gamma^{\prime}$ precipitates are mainly intragranular. During sub-solvus heat treatment at $1373 \mathrm{~K}\left(1100{ }^{\circ} \mathrm{C}\right)$, dissolution of the incoherent precipitates occurs through coarsening of the coherent intragranular population with only sporadic incoherent precipitates remaining. The prior induced deformation (strain and strain rate) influences the evolution of precipitate morphologies during cooling following heating to super-solvus temperature. Using numerical simulations, a quantitative calculation of the different precipitate morphologies was carried out during slow cooling from super-solvus temperature, $1443 \mathrm{~K}$ to $1373 \mathrm{~K}\left(1170{ }^{\circ} \mathrm{C}\right.$ to $\left.1100{ }^{\circ} \mathrm{C}\right)$.
\end{abstract}

https://doi.org/10.1007/s11661-019-05330-w

(C) The Author(s) 2019

\section{INTRODUCTION}

NI-BASED superalloys strengthened by the presence of a dispersion of coherent $\gamma^{\prime}\left(\mathrm{Ll}_{2}\right)$ precipitates in an FCC-disordered solid solution matrix of $\gamma$ (A2) phase find wide applications in aero-engine and land-based power generation designed for high-temperature applications. Specifically, for turbine disc applications, the powder metallurgy (PM) route is followed. Superalloy powders synthesized by gas atomization, hot isostatic pressing (HIP) followed by blind die compaction (upset), and hot extrusion are used to produce the billet. The billet is subsequently isothermally forged and then heat treated. The evolution of the microstructure, i.e., specifically the $\gamma^{\prime}$ precipitate morphology during these thermomechanical processes controls the grain

N. D'SOUZA, W. LI, and C. ARGYRAKIS are with the RollsRoyce plc, PO Box 31, Derby, DE24 8BJ, UK. G.D. WEST and C.D. SLATER are with the Warwick Manufacturing Group, University of Warwick, Coventry CV4 7AL, UK. Contact e-mail: c.d.slater@warwick.ac.uk

Manuscript submitted April 11, 2019.

Article published online June 26, 2019 size ${ }^{[1-4]}$ The grain size has a significant effect on the evolution of the flow stresses during forging. ${ }^{[2,5-10]}$ The evolution of the $\gamma^{\prime}$ precipitate morphology is influenced by the stress, plastic strain, and most importantly the strain rate. ${ }^{[4,11,12]}$ The 1 st population termed as primary $\gamma^{\prime}$ has the principal role of inhibiting grain growth during billet manufacture and forging by pinning the grain boundaries and are typically, 1 to $5 \mu \mathrm{m}$ in size. ${ }^{[13]}$ Thermomechanical operations carried out at temperatures where only these pinning particles are present in the microstructure (absence of secondary/tertiary populations, as they have lower solvus temperature compared to forging temperature) can be therefore carried out at decreased flow stresses. The evolution of flow stress under a range of thermomechanical treatments has been studied in Ni-based alloys encompassing total strain, strain rate and stress, and constitutive equations have been fitted to describe the behavior. Depending on the temperature/strain rates, either dynamic re-crystallization (DRX) occurs at high strain rates approaching $\sim 1 \mathrm{~s}^{-1}$, while at intermediate/lower strain rates, $\sim 10^{-3}$ to $10^{-2} \mathrm{~s}^{-1}$ super-plastic flow preceded by limited DRX occurs in the temperature range, $1273 \mathrm{~K}$ to $1423 \mathrm{~K}^{[5-9,14]}$ 
The motivation for this study stems from the fact that most prior studies have primarily focused on conditions of isothermal forging characterized by low strain rates, typically $\leq 0.1 \mathrm{~s}^{-1}$. There are fewer investigations at high strain rates, typically $\geq 1 \mathrm{~s}^{-1}$, which is akin to conditions associated with billet manufacture. At these high strain rates if DRX does not completely relax all the stress owing to the negligible deformation time ( $\Delta t \sim 5$ seconds and depending on the final plastic strain), reduction in the remnant dislocation density leads to meta-dynamic (post-dynamic) re-crystallization during cooling. ${ }^{[4,15]}$ Furthermore, under such extreme deformation conditions, both the morphology and spatial occurrence of $\gamma^{\prime}$ precipitates, i.e., inter/intragranular is determined by the strain rate. ${ }^{[12]}$ The significance of studying the precipitate evolution under conditions of billet manufacture is key, since anomalous grain growth and existence of un-re-crystallized powder particles existing within the billet will affect both the flow stress and two-phase microstructure that evolves during forging, which can adversely affect the mechanical properties of the component. ${ }^{[1]}$ Therefore,

1) The first objective in this study will be to explore the range of processing conditions and their effect on the morphology and crystallographic evolution of primary $\gamma^{\prime}$ precipitates.

2) Second, the role of heat treatment is also studied, specifically in relation to the subsequent extrusion stage in the processing sequence prior to isothermal forging.

3) It must be pointed out that the amount of primary $\gamma^{\prime}$ precipitates will in turn determine the extent of the intragranular secondary and tertiary precipitate populations. The secondary and tertiary sizes range typically between 100 to 400 and 5 to $50 \mathrm{~nm}$, respectively ${ }^{[16-19]}$ and are stabilized during subsequent post forging heat treatments. Optimization of their distribution confers the superior mechanical properties. Therefore, a third aim of this paper will quantitatively address the influence of the primary $\gamma^{\prime}$ precipitate distribution on these populations using numerical simulations.

The nominal composition of the Ni-based superalloy, RR1000 is given in Table I.

\section{EXPERIMENTAL METHOD}

The starting material condition corresponds to a sub-solvus as-HIPped billet from which Gleeble test specimens were machined. For compression testing, a Gleeble HDS-V40 was used in uniaxial mode. Samples, $10 \mathrm{~mm}$ diameter and $15 \mathrm{~mm}$ long, were machined from the as-HIP compact. Samples were loaded into the Gleeble machine with a layer of graphite and $\mathrm{Ta}$ on either end and $\mathrm{Ni}$ paste was used as a conductive adhesive. Two $0.3 \mathrm{~mm}$ holes were drilled into the centerline of the sample to a depth of $1 \mathrm{~mm}$ and a K-type thermocouple was "peened" to the sample thereby ensuring a good and consistent contact even under highly strained conditions where shape change during deformation would occur. Prior to commencing each test, the chamber was evacuated and back-filled with $\mathrm{Ar}$ three times before a final vacuum level of $1 \times 10^{-3}$ mbar was achieved. During heating, an initial preheat temperature of $373 \mathrm{~K}\left(100^{\circ} \mathrm{C}\right)$ was set to burn-off the conductive adhesive carrier and to volatilize any existing moisture. Table II presents the thermomechanical profiles for the compression tests.

Electron microscopy was carried out on metallurgical specimens that were ground and polished to $0.02 \mu \mathrm{m}$ surface finish in the as-polished condition. The sample matrix was analyzed using a Versa 3D FIB/FEG-SEM (FEI) equipped with an AztecSynergy (Oxford Instruments) analytical system comprising of an $\mathrm{XMax}^{\mathrm{N}} 80$ SDD Energy-Dispersive Spectrometer (EDS) and a Nordlys $\mathrm{Max}^{3}$ Electron Back-Scatter Diffraction (EBSD) camera. Images were taken at $5 \mathrm{kV}$ with a conventional Everhart Thornley Secondary Electron (SE) detector. EBSD was performed at $20 \mathrm{kV}$ using a nominal current of $12 \mathrm{nA}$ at $70 \mathrm{deg}$ tilt. EBSD maps were either exported directly from the Aztec software or in the case of Local Average Misorientation (LAM) from ICE (Oxford Instruments) analysis software. Energy-dispersive spectroscopy (EDS) maps were collected separately at $20 \mathrm{kV}$ and also at $10 \mathrm{kV}$ at zero tilt also with a nominal current of $12 \mathrm{nA}$ with a real acquisition time of approximately 15 minutes and an input count rate in the range (100 to 150$)$ kilo counts per second (kcps). This intermediate voltage was a good compromise between maintaining a sufficient spectral

Table I. Nominal Composition (Weight Percent) of the Ni-Based Superalloy, RR1000 ${ }^{[20]}$

\begin{tabular}{|c|c|c|c|c|c|c|c|c|c|c|}
\hline Co & $\mathrm{Cr}$ & Mo & $\mathrm{Ta}$ & $\mathrm{Ti}$ & $\mathrm{Al}$ & B & $\mathrm{C}$ & $\mathrm{Zr}$ & Hf & $\mathrm{Ni}$ \\
\hline$\overline{18.5}$ & 15 & 5 & 2 & 3.6 & 3 & 0.015 & 0.027 & 0.06 & 0.75 & balance \\
\hline
\end{tabular}

Table II. Summary of Thermal and Mechanical Profiles for the Uniaxial Compression Tests

\begin{tabular}{lcccc}
\hline $\begin{array}{c}\text { Test } \\
\text { Number }\end{array}$ & \multicolumn{1}{c}{ Heating } & $\begin{array}{c}\text { Nominal } \\
\text { Strain }\end{array}$ & $\begin{array}{c}\text { Strain Rate } \\
\left(\mathrm{s}^{-1}\right)\end{array}$ & \multicolumn{1}{c}{ Cooling } \\
\hline 1 & Heat to $1413 \mathrm{~K}\left(1140^{\circ} \mathrm{C}\right)$ at $10 \mathrm{~K} \mathrm{~s}^{-1}$ and hold for $5 \mathrm{~min}$ & 1 & 0.1 & $\mathrm{Cooling} \mathrm{at} 5 \mathrm{~K} \mathrm{~s}^{-1}$ up to \\
2 & Heat to $1373 \mathrm{~K}\left(1100^{\circ} \mathrm{C}\right)$ at $10 \mathrm{~K} \mathrm{~s}^{-1}$ and hold for $5 \mathrm{~min}$ & & 1 & $473 \mathrm{~K}\left(200{ }^{\circ} \mathrm{C}\right)$ \\
3 & & & 10 & \\
\hline
\end{tabular}


range (high $\mathrm{kV}$ ) and maximizing spatial resolution (low $\mathrm{kV})$. The composition of features of interest was quantified by extracting spectra from features of interest in the EDS maps. From combined EBSD/EDS done at $20 \mathrm{kV}$, the EDS map (Cr) was overlaid on the band contrast map EBSD map. While this was satisfactory for $1 \mathrm{~s}^{-1}$, owing to the large interaction volume, the resolution of small $\gamma^{\prime}$ precipitates was reduced for the larger strain rate, $10 \mathrm{~s}^{-1}$. To address this, the EDS data were re-collected from the same area at $10 \mathrm{kV}$ at zero tilt. Small distortions in the EBSD acquisition data collected at $70 \mathrm{deg}$ result in corresponding features not overlaying perfectly on the Cr EDS map acquired at zero tilt. Therefore, in case of the higher strain rate $\left(10 \mathrm{~s}^{-1}\right)$, the Cr EDS map was overlaid on the electron image, which was taken at zero tilt. Additionally, electron microscopy was also carried out on samples which were mechanically polished to $0.25 \mu \mathrm{m}$ finish and electro-etched in 10 pct phosphoric acid in methanol for 3 seconds using a 3-V voltage. A Philips XL30 FEG-SEM in the backscattered electron (BSE) mode was used to evaluate the $\gamma^{\prime}$ precipitates. Quantitative phase fraction analysis was performed using the ImageJ analysis software.

\section{RESULTS}

\section{A. Evolution of True Stress and True Strain During Hot Deformation (As-Forged)}

The true stress-strain curves obtained during hot deformation at $1373 \mathrm{~K}\left(1100^{\circ} \mathrm{C}\right)$ are presented in Figure 1 for the strain rates of 1 and $10 \mathrm{~s}^{-1}$ and correspond to sub-solvus conditions. Also included is the flow curve corresponding to deformation close to solvus $\left[1418 \mathrm{~K}\left(1145^{\circ} \mathrm{C}\right)\right]$ at $1413 \mathrm{~K}\left(1140{ }^{\circ} \mathrm{C}\right)$ for a strain rate of $0.1 \mathrm{~s}^{-1}$. In all cases, the samples were deformed to a final nominal strain of $\varepsilon=1$. The following observations can be made:

(i) The flow curves are characterized by the initial rapid increase in stress from work hardening up to a true strain of $\sim 0.04$, when a peak in the true stress is reached.

(ii) For the low strain rate, $0.1 \mathrm{~s}^{-1}$ and close to solvus temperatures, the stress remains constant over the entire range of strain. For increasing strain rates and sub-solvus temperature, the initial work hardening is followed by softening mechanisms beyond a threshold strain $(\sim 0.1$ for $\dot{\varepsilon}=1 \mathrm{~s}^{-1}$ and $\sim 0.15$ for $\dot{\varepsilon}=10 \mathrm{~s}^{-1}$ ) and resulting in a rapid decrease in the flow stress, $\Delta \sigma \sim 75 \mathrm{MPa}$ and $\Delta \sigma \sim 200 \mathrm{MPa}$ for the two cases, respectively.

During high-speed deformation most of the external mechanical work that is applied to the workpiece is transformed to heat. Although this adiabatic heating is not adequate to uniformly increase the temperature of the specimen and allow any significant heat exchange with the environment, the localized temperature gradient can contribute to microstructural changes. The "degree of effectiveness" of the process, which defines the fraction of the work that will be stored as thermal energy is often taken to be independent of temperature and has values ranging between 0.9 and $0.95 .^{[21,22]}$ The latter value has been considered in this work and used as an input in the commercial finite element code DEFORM $^{\circledR}$ where the compression tests have been

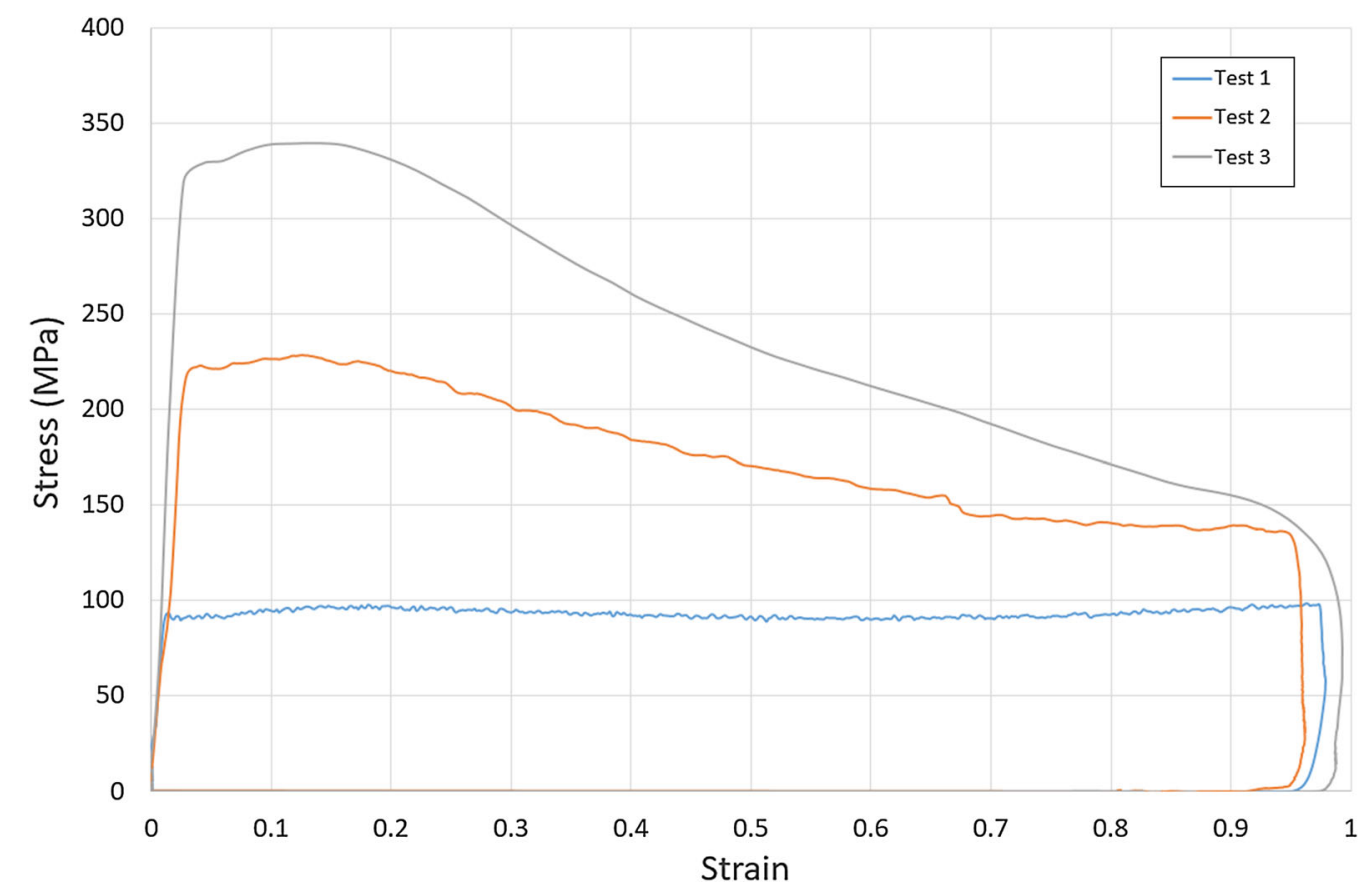

Fig. 1-Measured macroscopic true stress-true strain curves corresponding to strain rates; $\dot{\varepsilon}=0.1,1$, and $10 \mathrm{~s}^{-1}$, respectively, and achieving a final strain, $\varepsilon=1$. Tests were conducted at $1373 \mathrm{~K}\left(1100^{\circ} \mathrm{C}\right)$ for $\dot{\varepsilon}=1$ and $10 \mathrm{~s}^{-1}$, but at $1413 \mathrm{~K}\left(1140{ }^{\circ} \mathrm{C}\right)$ for $\dot{\varepsilon}=0.1 \mathrm{~s}^{-1}$. 


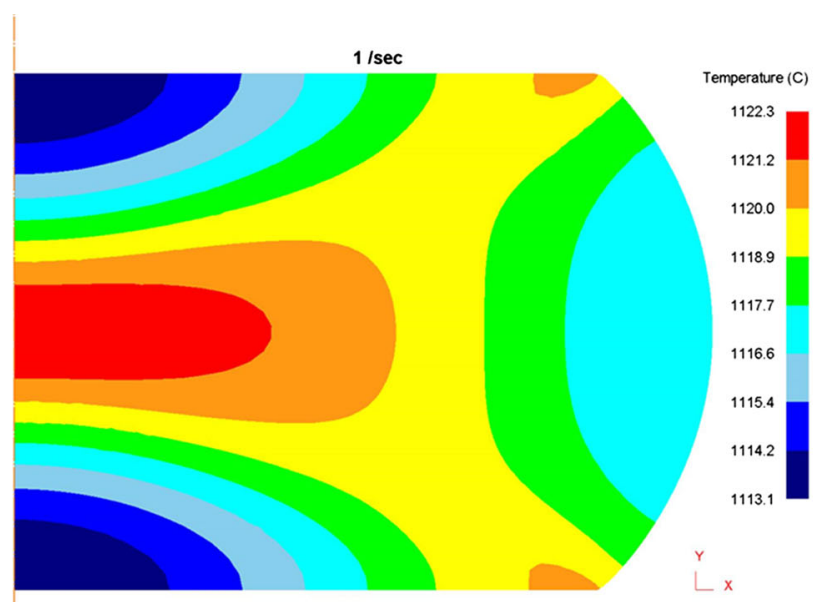

(a)

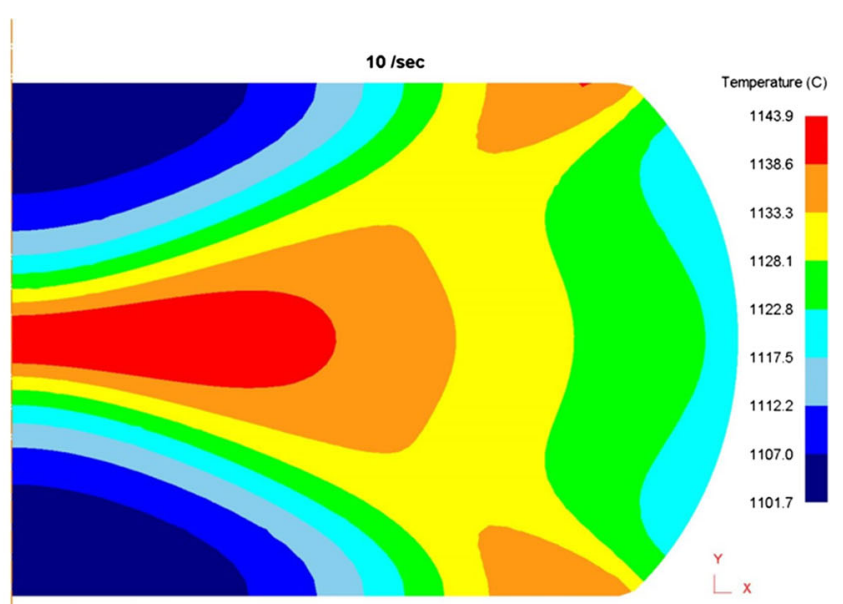

(b)

Fig. 2 - Calculated temperature contours showing adiabatic heating effects using the commercial finite element code DEFORM ${ }^{\circledR}$ across the cross section; (a) $\dot{\varepsilon}=1 \mathrm{~s}^{-1}$ and $(b) 10 \mathrm{~s}^{-1}$ for deformation at $1373 \mathrm{~K}\left(1100^{\circ} \mathrm{C}\right)$ and achieving a final strain, $\varepsilon=1$.

modeled. ${ }^{[23]}$ The model shows that at the nominal deformation temperature of $1373 \mathrm{~K}\left(1100{ }^{\circ} \mathrm{C}\right)$, a maximum increase in temperature of approximately $22 \mathrm{~K}$ and $44 \mathrm{~K}$ is obtained for $\dot{\varepsilon}=1$ and $10 \mathrm{~s}^{-1}$, respectively, as shown in Figures 2(a) and (b). The calculation of the strain contours is dependent on the friction coefficient between the compression plates and the work piece. The barreling effect along the specimen length was measured by sectioning the Gleeble specimen. Following an iterative process for the value of the apparent shear friction coefficient $(\mu)$ in the Finite Element (FE) model, with a final value set at 1.4, the measured deformed specimen dimensions corresponded closely to the calculated values in the simulation. This thereby provided an accurate strain contour as presented in Figures 3(a) and (b) corresponding to $\dot{\varepsilon}=1$ and $10 \mathrm{~s}^{-1}$, respectively. The following observations can be made from Figures 2 and 3 :

(iii) There is a direct correlation between the strain and temperature maps.

(iv) The strains at any spatial location are greater for $10 \mathrm{~s}^{-1}$. The peak strain $(\varepsilon \sim 1.69$ to 3.29$)$ is in a smaller width at the center $(\sim 0.5 \mathrm{~mm})$ compared with the lower strain rate $(\varepsilon \sim 1.26$ to $2.52)$, where the width is noticeably greater at the center $(\sim 1.2 \mathrm{~mm})$.

\section{B. Nucleation and Growth of Primary Gamma Prime Precipitates During Hot Deformation}

One of the principal mechanisms of flow softening at high strain rates is through dynamic re-crystallization (DRX), which subsequently controls the evolution of the microstructure. The initial condition of the samples corresponds to as-HIP. Accordingly, Figures 4(a) through (d) are low-magnification secondary electron images corresponding to as-HIP and as-forged for $\dot{\varepsilon}=0.1,1$ and $10 \mathrm{~s}^{-1}$, respectively, from the center of the sample, which is in the as-polished condition.
Higher-magnification images corresponding to (a) as-HIP are presented in (e), (f), while that for (c) $\dot{\varepsilon}=$ $1 \mathrm{~s}^{-1}$ are presented in $(\mathrm{g}),(\mathrm{h})$, and those for (d) $\dot{\varepsilon}=$ $10 \mathrm{~s}^{-1}$ are presented in (i), (j) respectively. The key observations are:

- $\quad \gamma$ Grain Size The grain size is coarsest in the case of $\dot{\varepsilon}=0.1 \mathrm{~s}^{-1}$ compared with all four conditions, while $\dot{\varepsilon}=1 \mathrm{~s}^{-1}$ has smallest grain size. It is not straightforward to measure a grain size from these electron images; this will be done using EBSD-derived grain orientation maps. There is distinct evidence of some non-recrystallized grains in the as-HIP sample and these appear sporadically within the microstructure in Figure 4(a).

- $\quad \gamma^{\prime}$ Precipitates Primary $\gamma^{\prime}$ is conventionally defined as precipitates occurring at grain boundaries, where these precipitates are irregular in shape and typically up to $1.5 \mu \mathrm{m}$ in size. ${ }^{[1,11,13]}$ There is a marked difference in precipitate evolution observed for the higher strain rates. For $\dot{\varepsilon}=1$ and $10 \mathrm{~s}^{-1}$, precipitates akin to primary are mainly intergranular for the lower strain rate and both inter/intragranular at the higher strain rate. Moreover, they are distinctly more globular, unlike in the as-HIP condition. Therefore, the nomenclature of "primary" will be modified to also include the intragranular precipitates in Figures 4(h) and (j). In the as-HIP condition, a tri-modal distribution of precipitates is observed, with the secondary and tertiary precipitates being coarser and therefore visible, unlike in the forged condition.

The role of increasing strain rate on grain size within the central region of the specimen can be observed from EBSD measurements. Figure 5(a) is a band contrast map and (b) is a typical inverse pole figures (IPF) map. Since the purpose of this is to show relative orientation of neighboring grains, it was found for this case that the choice of axes is not important so only a single-grain orientation map for each sample is displayed, where the 


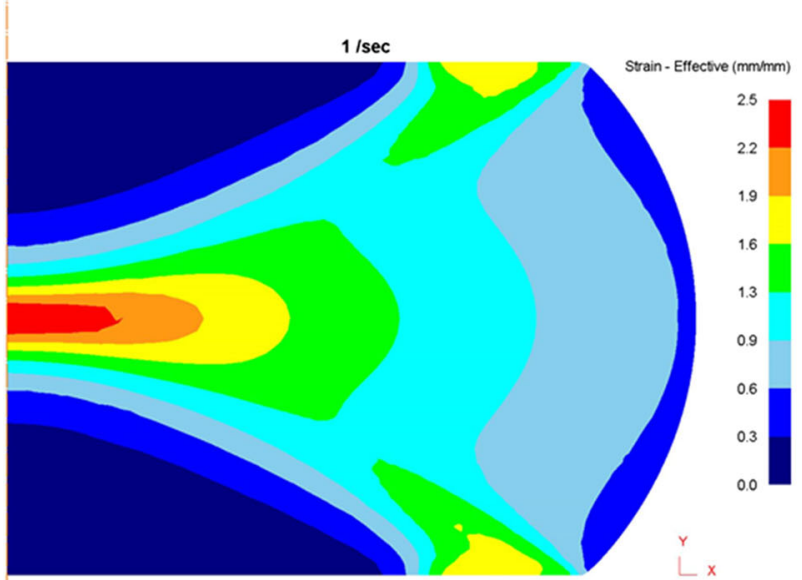

(a)

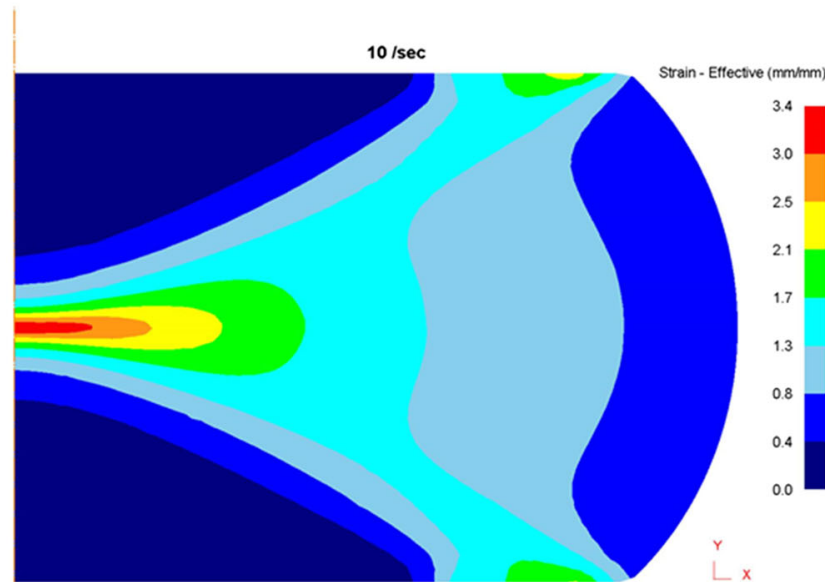

(b)

Fig. 3 - Calculated true stress-true strain contour plots using the commercial finite element code DEFORM ${ }^{\circledR}$ across the cross section for deformation at $1373 \mathrm{~K}\left(1100{ }^{\circ} \mathrm{C}\right) ;(a) \dot{\varepsilon}=1 \mathrm{~s}^{-1}$ and $(b) 10 \mathrm{~s}^{-1}$ and achieving a final strain, $\varepsilon=1$.

deformation direction is along the vertical ( $Y$-axis) in Figure 5(b). Moreover, since Ti preferentially partitions to $\gamma^{\prime}$, while $\mathrm{Cr}$ strongly segregates to $\gamma$ phase, either Ti or Cr EDS maps can be used to identify $\gamma^{\prime}$ precipitates. In this case, the Cr EDS map is used, as in Figure 5(c). In Figure 5(d), the EDS map is overlaid on to the EBSD map, so that the spatial location of the precipitates within the microstructure can be visualized. The band contrast overlaid on the local average misorientation (LAM) map is presented in Figure 5(e). Similarly, Figures 6(a) through (c) refer to the band contrast, inverse pole figures (IPF), and Cr EDS maps respectively for $=10 \mathrm{~s}^{-1}$. Accordingly, in Figure 6(d), the EDS map is overlaid on to the corresponding electron image, where the grain boundaries can be observed. Figure 6(e) shows the corresponding band contrast overlaid on the local average misorientation (LAM) map. The following key observations can be made:

- Incoherent/coherent $\gamma^{\prime}$ Precipitates $\gamma^{\prime}$ precipitates predominantly occur with high-angle boundaries with the neighboring $\gamma$ grain(s) and the interface with $\gamma$ phase is therefore incoherent. In case of $\dot{\varepsilon}=1 \mathrm{~s}^{-1}$, the precipitates are predominantly incoherent and intergranular. However, some coherent precipitates are also observed, as highlighted in Figure 5(d). While these are intergranular, they possess the same orientation as the $\gamma$ grain into which they grow and not all of the $\gamma$ grain has been consumed. In case of $\dot{\varepsilon}=10 \mathrm{~s}^{-1}$, both inter/intragranular $\gamma^{\prime}$ precipitates are observed, but unlike the lower strain rate all primary $\gamma^{\prime}$ is incoherent. For $\dot{\varepsilon}=1 \mathrm{~s}^{-1}$, some of the $\gamma$ grains show a LAM of typically $3 \mathrm{deg}$, but in case of $\dot{\varepsilon}=10 \mathrm{~s}^{-1}$, a virtually strain-free matrix is observed. However, in case of $\dot{\varepsilon}=10 \mathrm{~s}^{-1}$, regions with the highest LAM values occur within many intragranular incoherent $\gamma^{\prime}$ precipitates, while sporadic incoherent intergranular $\gamma^{\prime}$ precipitates are associated with LAM values of typically $3 \mathrm{deg}$. No variation in the concentration of the key segregating alloying elements: $\mathrm{Co}, \mathrm{Cr}$,
Mo, Ti, and Ta was observed and is summarized in Table III. The measurements are however constrained by limits of spatial resolution.

Consequently, calculation of the $\gamma$ grain size becomes less than straightforward, as it also includes the contribution of the incoherent $\gamma^{\prime}$ precipitates. A possible method of delineation between $\gamma$ grains and $\gamma^{\prime}$ precipitates involves the elimination of grains whose number of pixels just exceeded the area of the largest $\gamma^{\prime}$ precipitate in the map. However, this method will also result in the exclusion of $\gamma$ grains sectioned far from their centroids and has limitations. ${ }^{[12]}$ Therefore, in case of $\dot{\varepsilon}=1 \mathrm{~s}^{-1}$, the intergranular incoherent $\gamma^{\prime}$ precipitates are not delineated from $\gamma$ grains and for a collection of 479 grains, the average grain size is $1.46 \mu \mathrm{m}$, with a maximum of $5.4 \mu \mathrm{m}$ and minimum of $0.5 \mu \mathrm{m}$ and which includes averages of $\gamma$ and $\gamma^{\prime}$ precipitates. In case of $\dot{\varepsilon}=10 \mathrm{~s}^{-1}$, this becomes less reliable given the smaller distribution of grains, i.e., 145 grains and the marked increase in intragranular incoherent $\gamma^{\prime}$ precipitates. Consequently, measurement of grain size is not attempted, but it suffices to note that from comparison of Figures 5(a), (b) and 6(a), (b), there is a near twofold increase in grain size for $\dot{\varepsilon}=10 \mathrm{~s}^{-1}$ when comparing the larger grains.

Table IV summarizes the observations of $\gamma$ grains and primary incoherent $\gamma^{\prime}$ precipitates in as-HIP and forged conditions, i.e., $\dot{\varepsilon}=1$ and $10 \mathrm{~s}^{-1}$.

Since there is a variation in plastic strain as well as adiabatic heating effects from the surface to the center, c.f. Figures 2 and 3, a comparison of the intra/intergranular $\gamma^{\prime}$ precipitate distribution across the specimen cross section was made. Figures 7(a) through (c) are backscattered electron (BSE) images showing the precipitate distributions on sections with increasing distance from the surface, with (c) being at the center corresponding to $\dot{\varepsilon}=1 \mathrm{~s}^{-1}$, while Figures 7(d) through (f) refer to $\dot{\varepsilon}=10 \mathrm{~s}^{-1}$, with (f) being at the center. These sections have been etched to preferentially attack $\gamma$ 
$100 \mu \mathrm{m}$

(a)

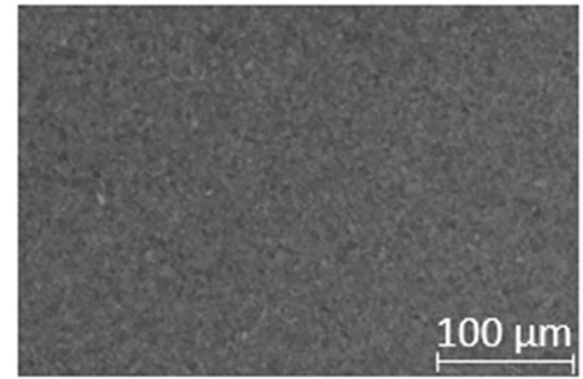

(c)

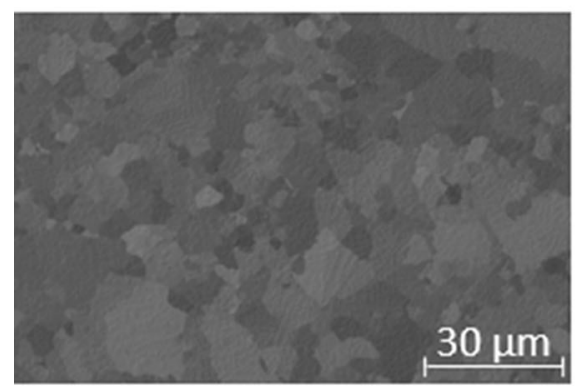

(e)

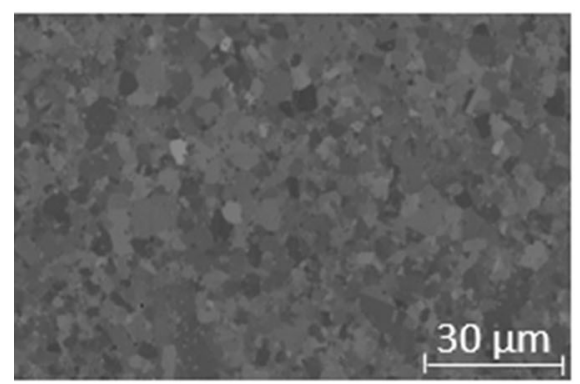

(g)

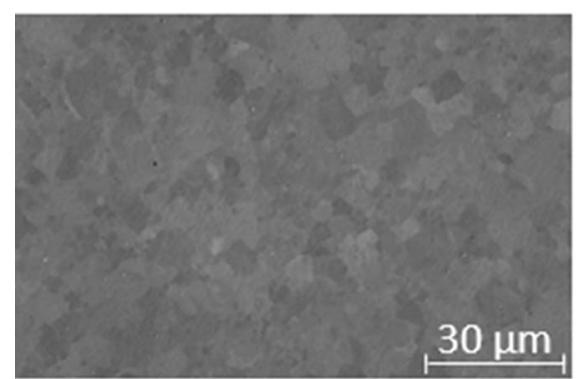

(i)

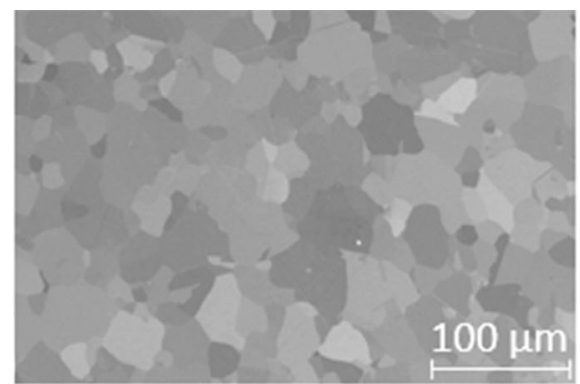

(b)

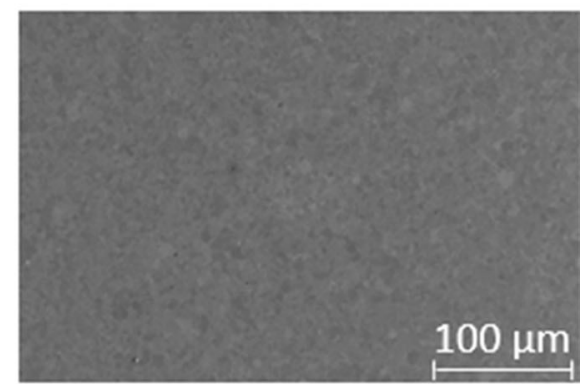

(d)

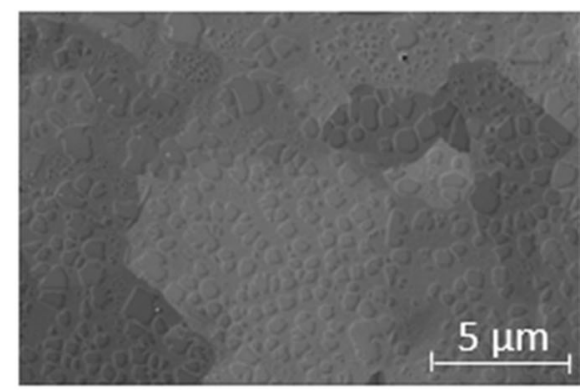

(f)

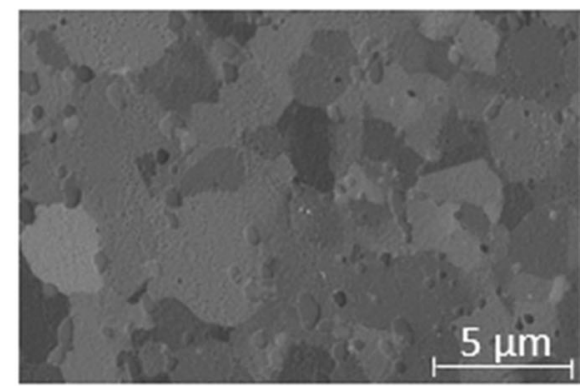

(h)

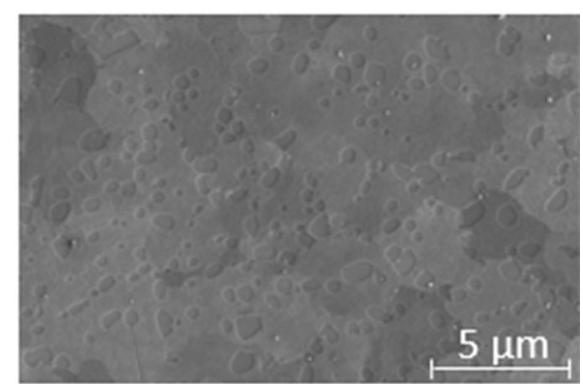

(j) 
4 Fig. 4-Secondary electron images of as-HIP and as-forged (Gleeble tested) samples in as-polished condition; $(a)$ to $(d)$ are low-magnification images corresponding to as-HIP, $\dot{\varepsilon}=0.1$, 1 , and $10 \mathrm{~s}^{-1}$, respectively, from the center of the sample. (e), $(f)$ are higher-magnification images corresponding to (a); as-HIP, while $(g)$, (h) are higher-magnification images corresponding to (c); $\dot{\varepsilon}=1 \mathrm{~s}^{-1}$ and $(i),(j)$ are higher-magnification images corresponding to (d); $\dot{\varepsilon}=$ $10 \mathrm{~s}^{-1}$, respectively.

phase and therefore $\gamma^{\prime}$ precipitates appear bright in the BSE images. The following observations can be made:

- $\gamma^{\prime}$ Precipitate Distribution There is a marked decrease in the number of un-recrystallized powder particles (originating in the as-HIP condition) with increasing distance from the surface and completely absent at the center. Aligned $\gamma^{\prime}$ precipitates are clearly observed within these un-recrystallized particles. There is also a marked decrease in precipitate size at the center compared with the surface, specifically for $\dot{\varepsilon}=1 \mathrm{~s}^{-1}$.

It also is pertinent to compare the evolution of $\gamma$ grain size as well as the primary $\gamma^{\prime}$ size and distribution with that in ${ }^{[12]}$ for comparable hot-working conditions. While the primary $\gamma^{\prime}$ size $(\sim 0.5 \mu \mathrm{m})$ and distribution (predominantly intragranular at high strain rates) are comparable in ${ }^{[12]}$ and in our study, there is a marked difference in the $\gamma$ grain size. The lower values in our study can be explained by the lower hot-working

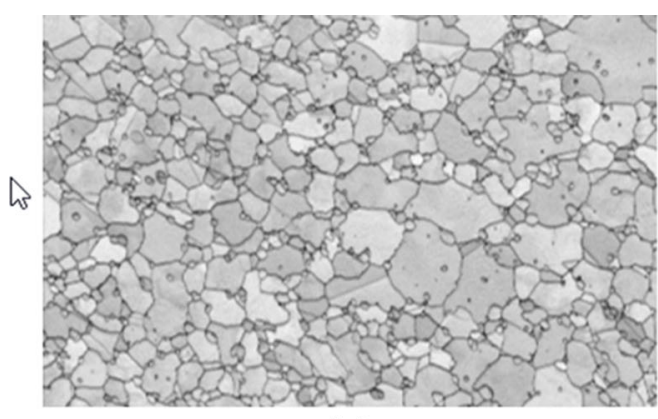

(a)

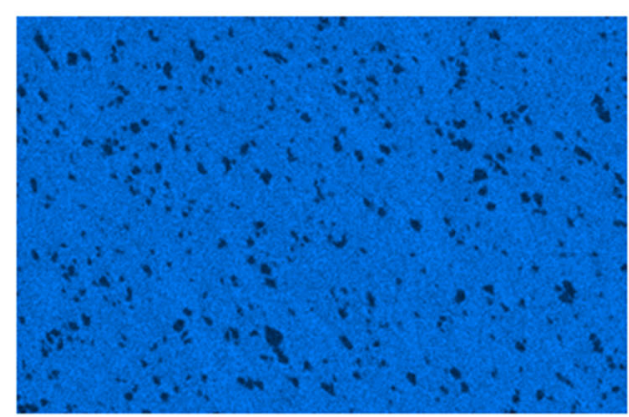

(c)

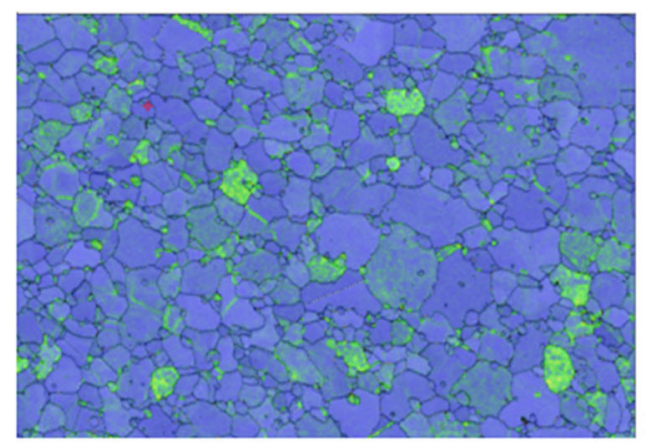

(e)

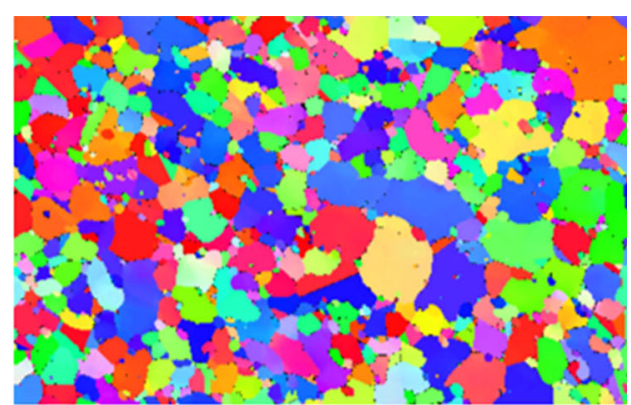

(b)

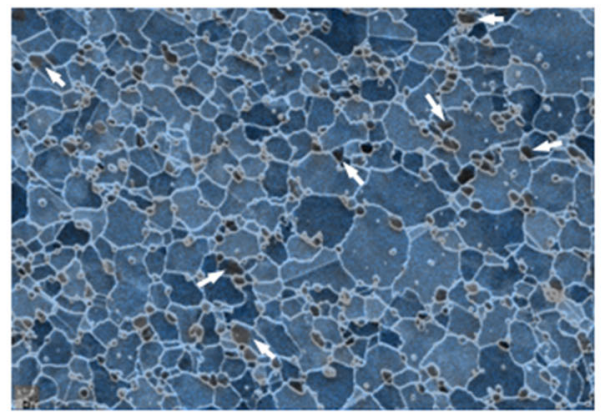

(d)

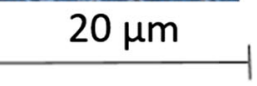

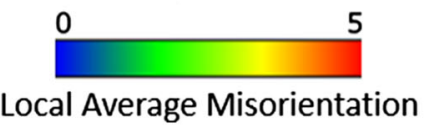

Local Average Misorientation

Fig. 5-EBSD and elemental composition maps obtained using energy-dispersive spectroscopy (EDS); $(a)$ is band contrast, $(b)$ inverse pole figure (IPF), (c) Cr EDS map, (d) overlaid EBSD and Cr EDS map, (e) overlaid band contrast on local average misorientation map corresponding to $\dot{\varepsilon}=1 \mathrm{~s}^{-1}$ at $1373 \mathrm{~K}\left(1100^{\circ} \mathrm{C}\right)$. White arrows in (d) show primary $\gamma^{\prime}$ intergranular precipitates coherent with matrix $\gamma$ grain. 


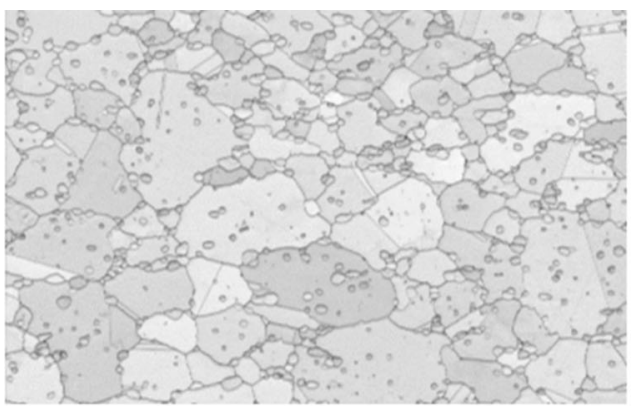

(a)

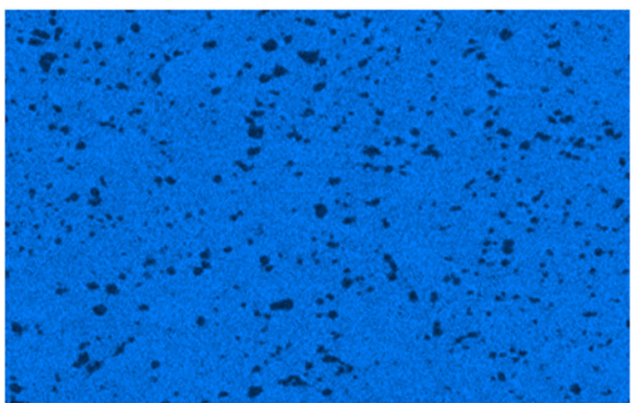

(c)

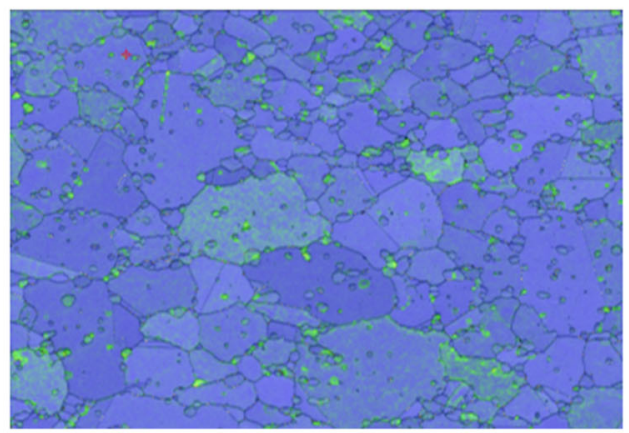

(e)

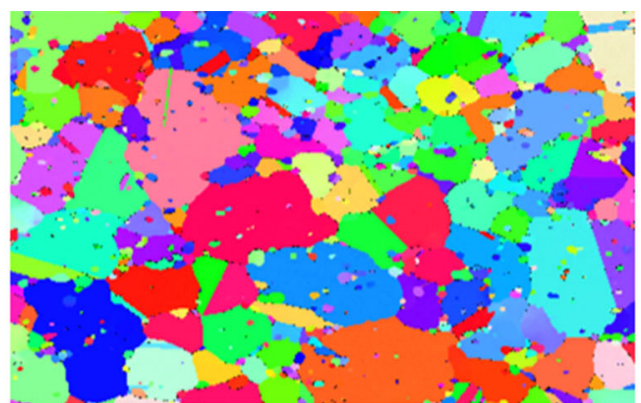

(b)

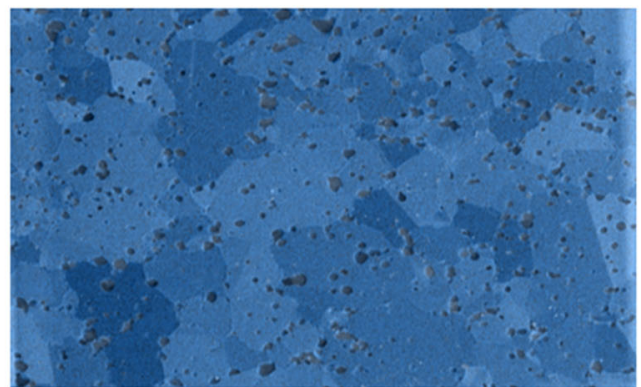

(d)

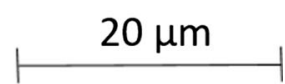

0

Local Average Misorientation

Fig. 6-EBSD and elemental composition maps obtained using energy-dispersive spectroscopy (EDS); $(a)$ is band contrast, $(b)$ inverse pole figure (IPF), $(c)$ Cr EDS map, $(d)$ overlaid electron image and Cr EDS map, $(e)$ overlaid band contrast on local average misorientation map corresponding to $\dot{\varepsilon}=10 \mathrm{~s}^{-1}$ at $1373 \mathrm{~K}\left(1100^{\circ} \mathrm{C}\right)$.

Table III. Concentration of Key Segregating Elements Within Primary $\gamma^{\prime}$ Composition (Weight Percent) Corresponding to As-Forged Conditions

\begin{tabular}{lccccc}
\hline $\mathrm{Al}$ & $\mathrm{Ti}$ & $\mathrm{Cr}$ & $\mathrm{Co}$ & $\mathrm{Mo}$ & $\mathrm{Ta}$ \\
\hline $4.0 \pm 0.15$ & $6.8 \pm 0.26$ & $3.3 \pm 0.30$ & $11.8 \pm 0.77$ & $1.1 \pm 0.18$ & $4.7 \pm 0.11$ \\
\hline Included is the standard deviation. & & & \\
\hline
\end{tabular}

temperature, i.e., $45 \mathrm{~K}$ below the solvus, unlike that in, ${ }^{[12]}$ where it is $22 \mathrm{~K}$ below solvus.

\section{Coherent Gamma Prime Precipitate Morphology After Hot Deformation-Sub-Solvus Isothermal and Super-Solvus Slow Cooling}

1. Sub-solvus temperature, $1373 \mathrm{~K}\left(1100^{\circ} \mathrm{C}\right)$

The evolution of $\gamma^{\prime}$ precipitates after isothermal solutioning at sub-solvus, $1373 \mathrm{~K} \quad\left(1100^{\circ} \mathrm{C}\right)$ for
90 minutes followed by water quench was investigated at strain rates of 1 and $10 \mathrm{~s}^{-1}$. Accordingly, Figures 8(a), (b) and 9(a), (b) are low- and high-magnification BSE images for the near-surface and center locations, respectively, for $\dot{\varepsilon}=1 \mathrm{~s}^{-1}$, while Figures 8(c), (d) and 9(c), (d) correspond to low- and high-magnification BSE images for the near-surface and center locations, respectively, for $\dot{\varepsilon}=10 \mathrm{~s}^{-1}$. The effect of annealing on the precipitate orientation at the center is presented in Figures 10 and 11 corresponding to $\dot{\varepsilon}=1$ 
and $10 \mathrm{~s}^{-1}$, respectively, where (a) through (d) refer to the band contrast, IPF, electron image, and $\mathrm{Cr}$ EDS map, respectively. The following observations can be made:

(i) $\gamma^{\prime}$ Precipitate Morphology Un-recrystallized powder particles are observed at the surface, where $\gamma^{\prime}$ precipitates are clearly observed within these particles, Figures 8(a) and (c). Coarsening of the precipitates is also observed for both strain rates, c.f., the deformed microstructure in Figures 4(g) through (j). An outline of the grain boundaries, as well as prior particle boundaries (PPB's) can be observed, Figure 9(c). There is a prominent intragranular precipitate population for $\dot{\varepsilon}=10 \mathrm{~s}^{-1}$, Figure 11(c). There is also an increased precipitate fraction at the center for the higher strain rate, Figures $8(\mathrm{~b})$ and (d). It must be emphasized that this measured precipitate fraction will preclude any distribution that cannot be resolved at this magnification, i.e., fine size precipitates but will include the coherent population in addition to the initial incoherent primary $\gamma^{\prime}$. Therefore, care must be exercised in any interpretation from image analysis as reported below.

- $\dot{\varepsilon}=1 \mathrm{~s}^{-1}$ : surface $=[11.4 \pm 0.07] \mathrm{pct}$, center: $[12.2 \pm 0.57]$ pct.

- $\dot{\varepsilon}=10 \mathrm{~s}^{-1}$ : surface $=[11.2 \pm 0.35] \mathrm{pct}$, center: $[16.1 \pm 0.60]$ pct.

(ii) $\gamma^{\prime}$ Precipitate Orientation There is marked decrease in the number of incoherent inter/ intragranular $\gamma^{\prime}$ precipitates for $\dot{\varepsilon}=10 \mathrm{~s}^{-1}$ compared with the as-forged condition. In the case of $\dot{\varepsilon}=1 \mathrm{~s}^{-1}$, there is also a significant reduction of intergranular incoherent precipitates, c.f. Figures 10 and 11.

It can be observed unequivocally that following sub-solvus heat treatment most of the initial incoherent primary $\gamma^{\prime}$ precipitates have transformed to a coherent population with sporadic distribution of remnant incoherent precipitates.

2. Super-solvus temperature, $1443 \mathrm{~K}\left(1170{ }^{\circ} \mathrm{C}\right)$

The evolution of $\gamma^{\prime}$ precipitates after heating as-forged samples $\left(\dot{\varepsilon}=1\right.$ and $\left.10 \mathrm{~s}^{-1}\right)$ to the super-solvus temperature, $1443 \mathrm{~K}\left(1170{ }^{\circ} \mathrm{C}\right)$ followed by slow cooling at $0.017 \mathrm{~K} \mathrm{~s}^{-1}\left(1 \mathrm{~K} \mathrm{~min}^{-1}\right)$ up to $1373 \mathrm{~K}\left(1100{ }^{\circ} \mathrm{C}\right)$ and subsequent quenching was investigated. Figures 12(a) through (d) are backscattered electron images from etched sections corresponding to as-HIP, $\dot{\varepsilon}=0.1,1$ and $10 \mathrm{~s}^{-1}$, respectively. There are two distinct precipitate morphologies observed, blocky intergranular and dendritic intragranular. There is an increasing precipitate fraction encompassing both morphologies from as-HIP to increasing strain rates, where at lower strain rates dendritic $\gamma^{\prime}$ prevails, but there is an increasing contribution from the intergranular morphology with increasing strain rate. The measured precipitate fraction from image analysis is as follows: 


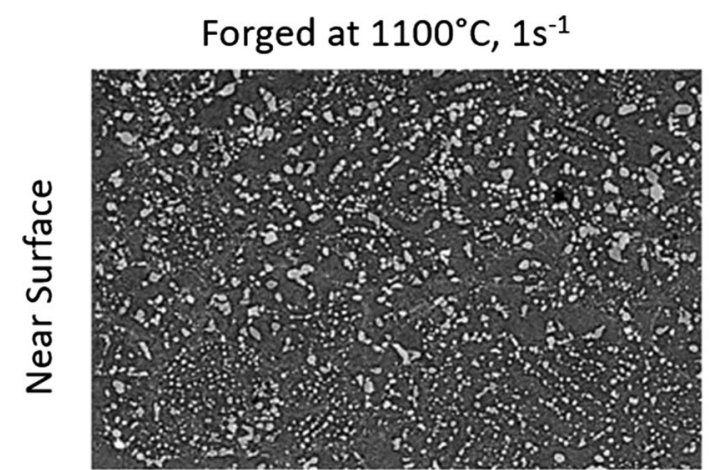

(a)

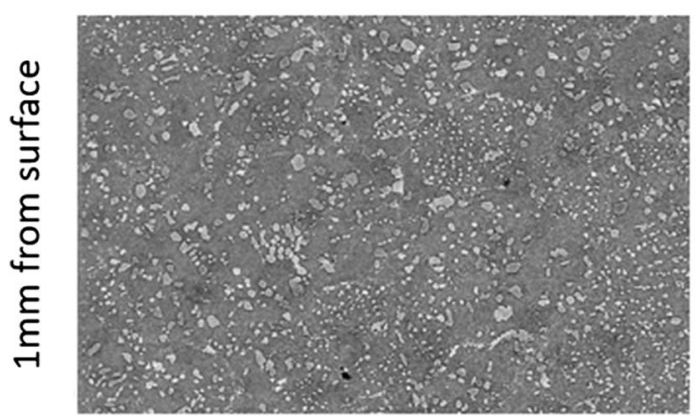

(b)

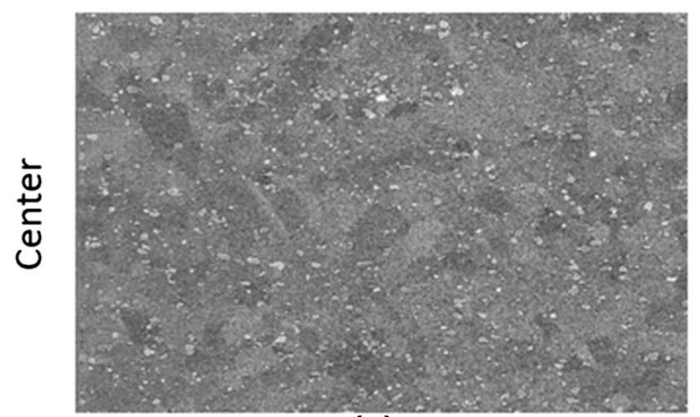

(c)

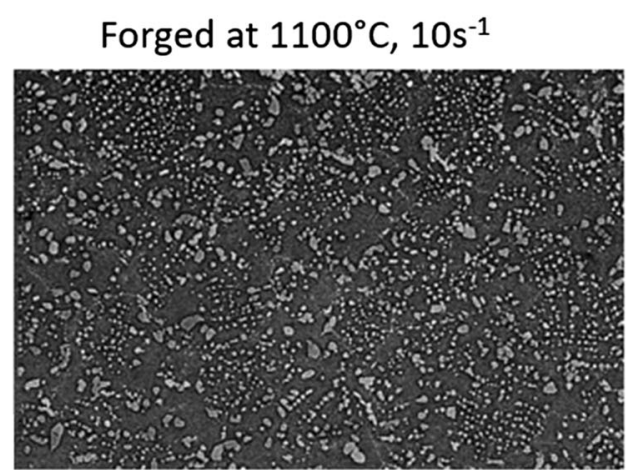

(d)

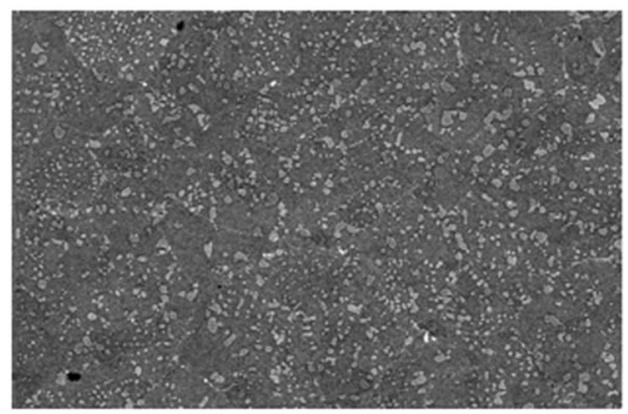

(e)

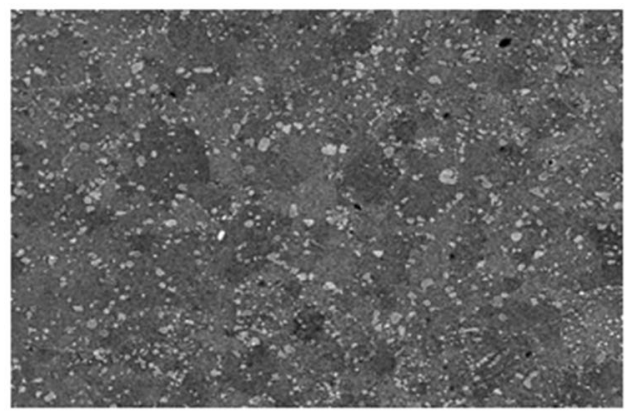

(f)

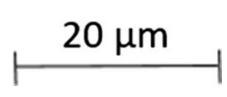

Fig. 7-Backscattered electron images from etched sections (etched with phosphoric acid) corresponding to different strain rates in Gleeble testing at $1373 \mathrm{~K}\left(1100{ }^{\circ} \mathrm{C}\right)$ and with increasing distance from the surface; $(a)$ to $(c)$, with $(\mathrm{c})$ being center for $\dot{\varepsilon}=1 \mathrm{~s}^{-1}$ and $(d)$ to $(f)$, with $(\mathrm{f})$ being center for $\dot{\varepsilon}=10 \mathrm{~s}^{-1}$.

$$
\begin{aligned}
& \text { As-Hip: center }=4.5 \mathrm{pct} \text {. } \\
& \dot{\varepsilon}=0.1 \mathrm{~s}^{-1}: \text { surface }=5.7 \mathrm{pct} \text {, center }: 5.7 \mathrm{pct} \\
& \dot{\varepsilon}=1 \mathrm{~s}^{-1}: \text { surface }=[7.6 \pm 0.85] \mathrm{pct}, \text { center }: \\
& {[7.8 \pm 0.07] \mathrm{pct}} \\
& \dot{\varepsilon}=10 \mathrm{~s}^{-1} \text { : surface }=[9.5 \pm 0.95] \text { pct, center : } \\
& {[11.9 \pm 0.70] \text { pct. }}
\end{aligned}
$$

\section{DISCUSSION}

The evolution of the microstructure in the as-forged, sub-solvus isothermal heat treatment, and continuous cooling from super-solvus temperature will be discussed.

\section{A. As-Forged Condition}

\section{Driving and retarding forces for $D R X$}

The flow stress is determined by the competition between work hardening that increases the dislocation density on the one hand and strain softening from recovery through dislocation annihilation and dynamic re-crystallization (DRX), where in the latter there is the nucleation and growth of strain-free $\gamma$ grains. ${ }^{[15]}$ In case of $\dot{\varepsilon}=0.1 \mathrm{~s}^{-1}$, the grain size is coarser than the starting as-HIP condition, Figures 4(a) and (b). The absence of stress decay following reaching the peak stress, as in Figure 1, clearly indicates the absence of DRX. Therefore, the increase in grain size occurs from grain growth at close to solvus temperature, where any Zener pinning from the precipitates is minimum. However, for $\dot{\varepsilon}=1$ and $10 \mathrm{~s}^{-1}$, not only does the peak flow stress increase with increasing strain rate, but there is also concomitant 


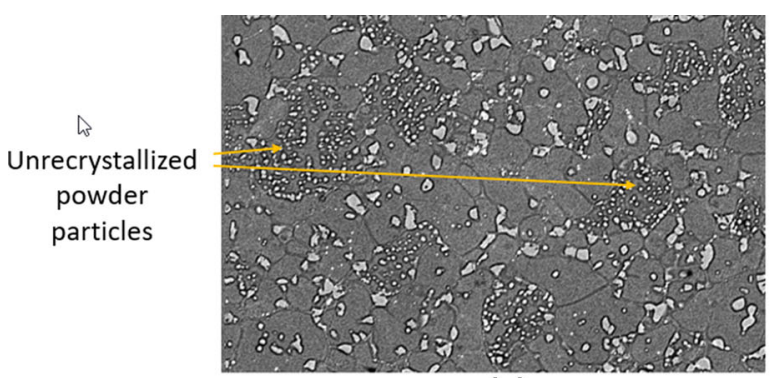

(a)

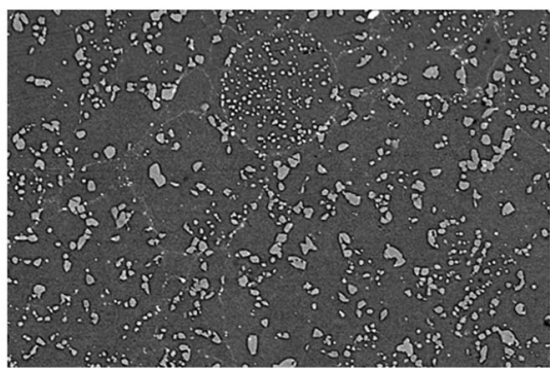

(c)

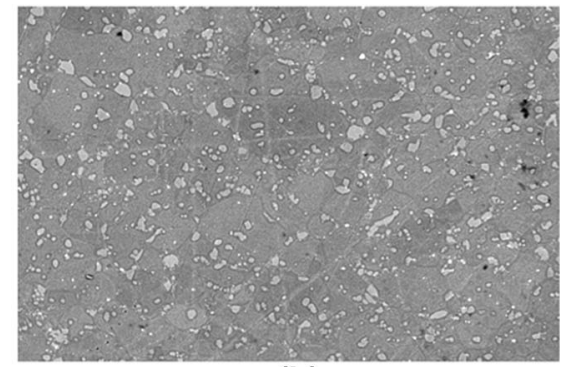

(b)

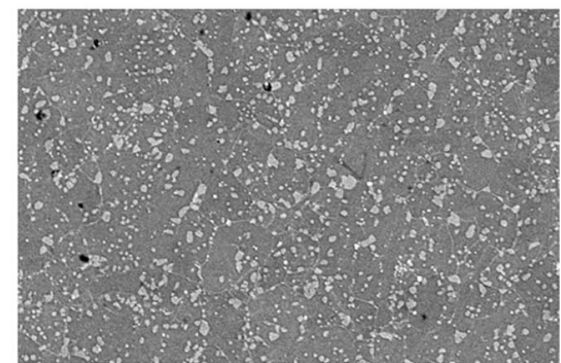

(d)

$20 \mu \mathrm{m}$

Fig. 8-Low-magnification backscattered electron images from etched sections (etched with phosphoric acid) after isothermal solutioning at $1373 \mathrm{~K}\left(1100^{\circ} \mathrm{C}\right)$ for $90 \mathrm{~min}$ and water quench (WQ) corresponding to different strain rates in Gleeble testing and with increasing distance from the surface; (a) surface, (b) center for $\dot{\varepsilon}=1 \mathrm{~s}^{-1}$ and (c) surface, (d) center for $\dot{\varepsilon}=10 \mathrm{~s}^{-1}$.

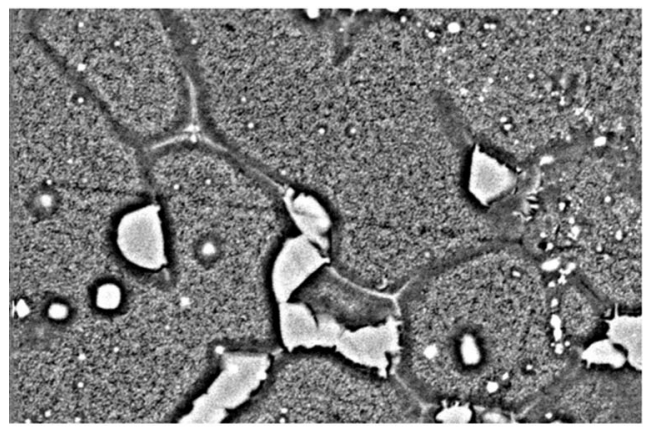

(a)

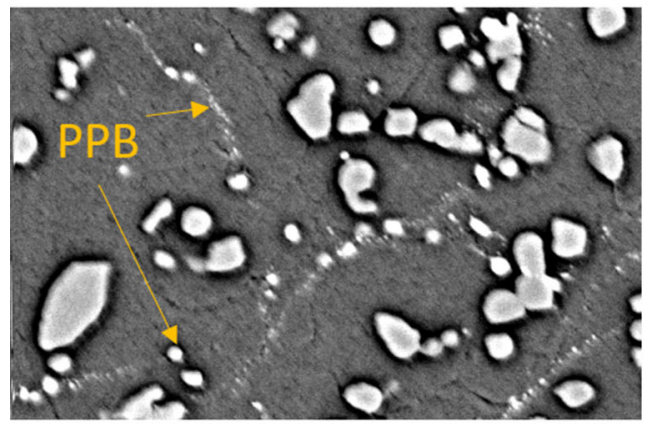

(c)

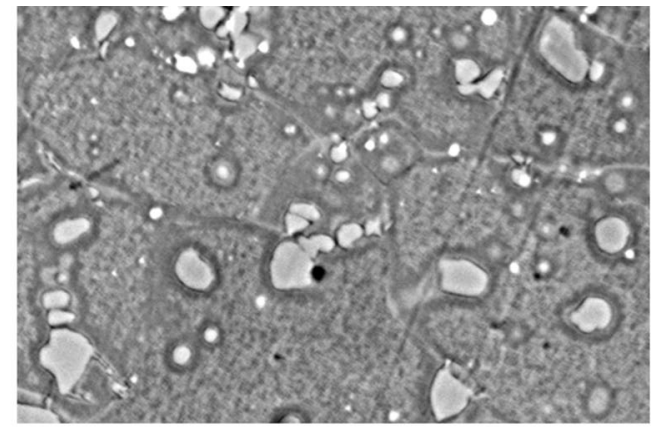

(b)

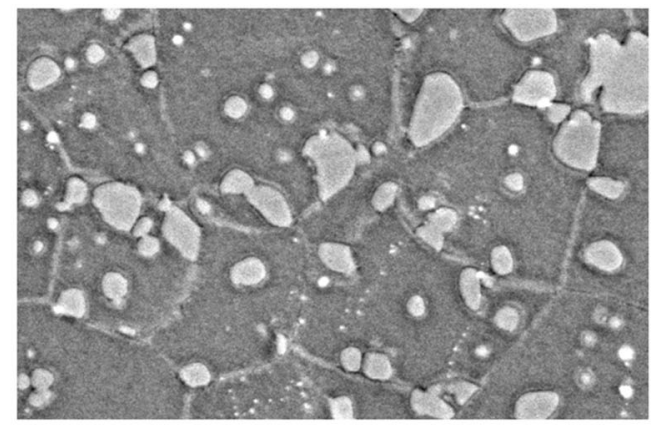

(d)

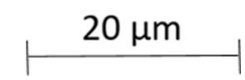

Fig. 9-High-magnification backscattered electron images from etched sections (etched with phosphoric acid) after isothermal solutioning at $1373 \mathrm{~K}\left(1100{ }^{\circ} \mathrm{C}\right)$ for $90 \mathrm{~min}$ and water quench (WQ) corresponding to different strain rates in Gleeble testing and with increasing distance from the surface; (a) surface, $(b)$ center for $\dot{\varepsilon}=1 \mathrm{~s}^{-1}$ and $(c)$ surface, $(d)$ center for $\dot{\varepsilon}=10 \mathrm{~s}^{-1}$.

greater stress decay observed at the higher strain rate. This is a direct manifestation of the occurrence of DRX. As a comparison, the extent of flow softening for $\dot{\varepsilon}=1$ and $10 \mathrm{~s}^{-1}$ is markedly greater than that reported in References 5-7 but comparable to that reported in Reference 2 and encompassing comparable range of 


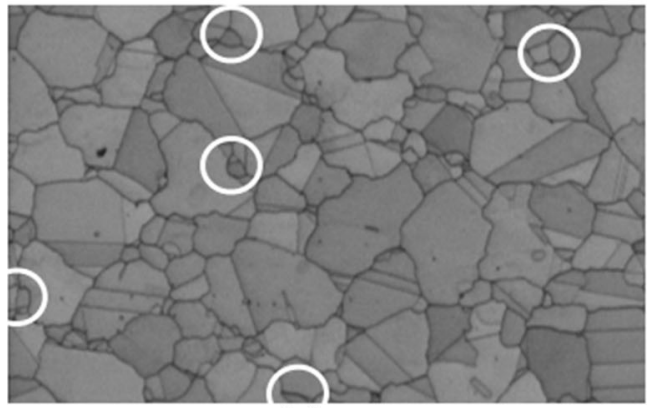

(a)

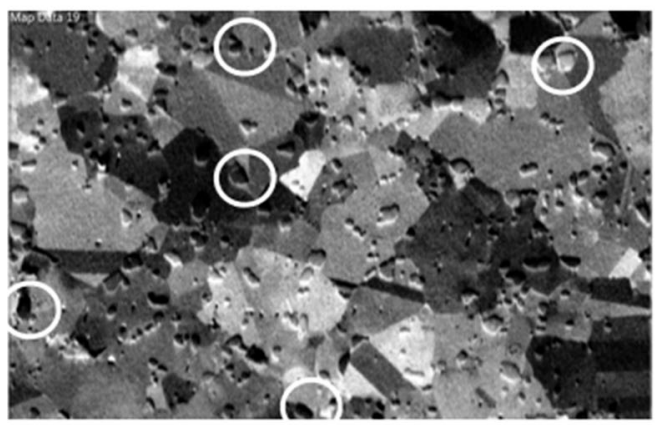

(c)

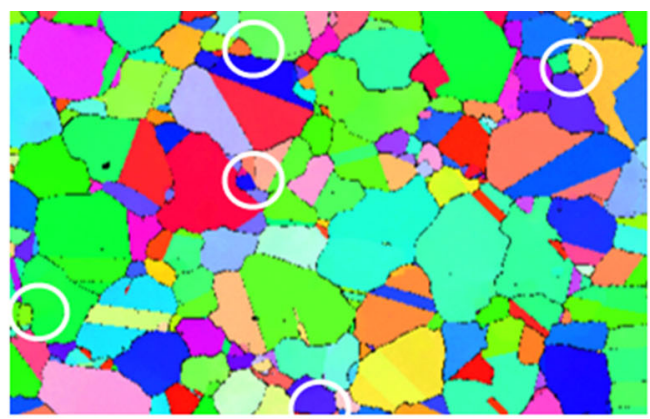

(b)

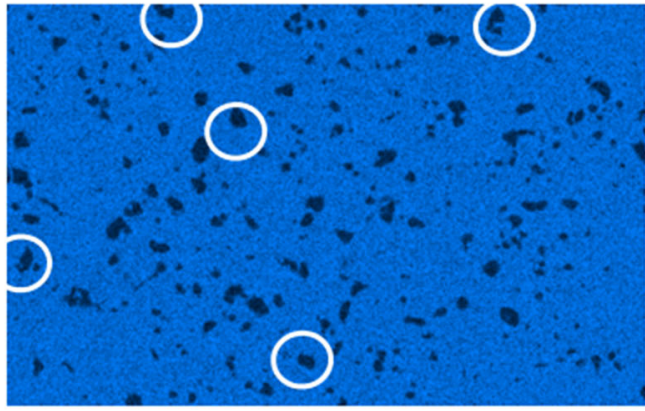

(d)

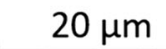

Fig. 10 - Evolution of $\gamma^{\prime}$ after isothermal solutioning at $1373 \mathrm{~K}\left(1100{ }^{\circ} \mathrm{C}\right)$ for 90 min followed by water quench for $\dot{\varepsilon}=1 \mathrm{~s}^{-1} ;(a)$ band contrast, $(b)$ inverse pole figure (IPF), $(c)$ forward scattered electron image, and (d) Cr EDS map.

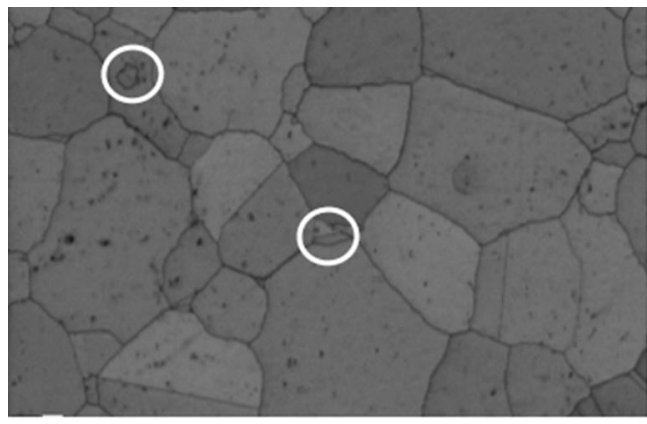

(a)

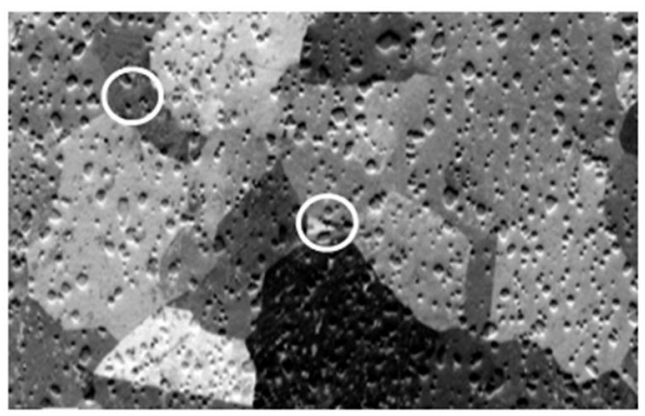

(c)

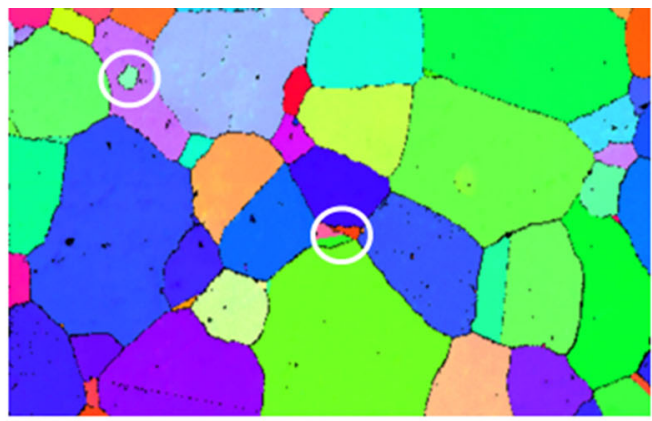

(b)

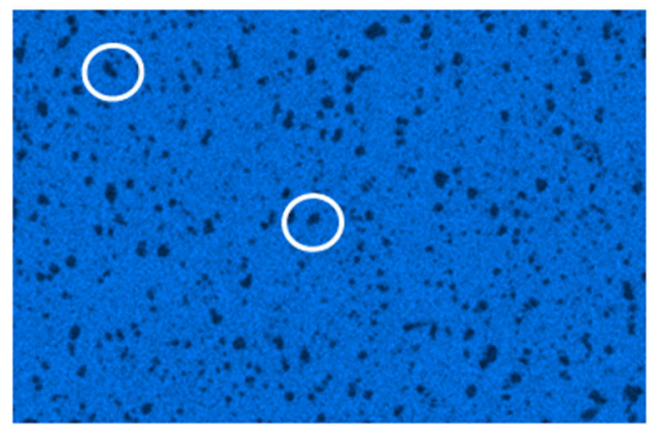

(d)

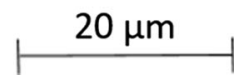

Fig. 11-Evolution of $\gamma^{\prime}$ after isothermal solutioning at $1373 \mathrm{~K}\left(1100{ }^{\circ} \mathrm{C}\right)$ for 90 min followed by water quench for $\dot{\varepsilon}=10 \mathrm{~s}^{-1} ;(a)$ band contrast, (b) inverse pole figure (IPF), (c) forward scattered electron image, and (d) Cr EDS map. 


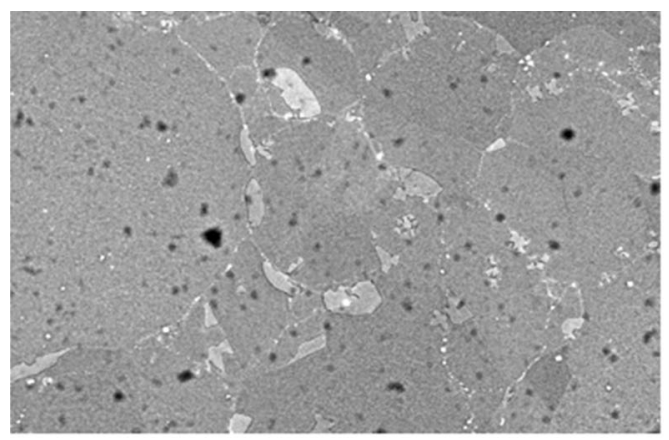

(a)

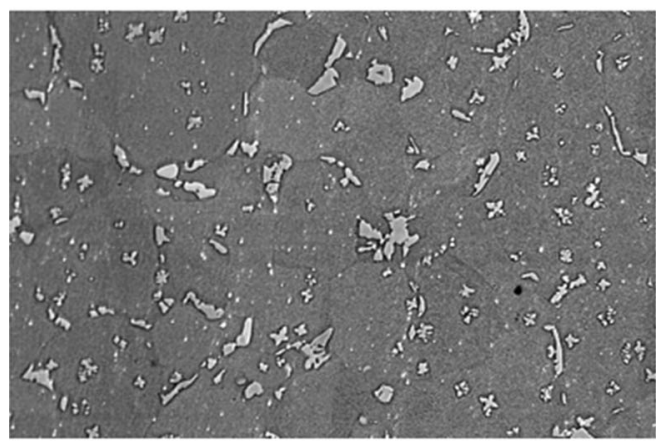

(c)

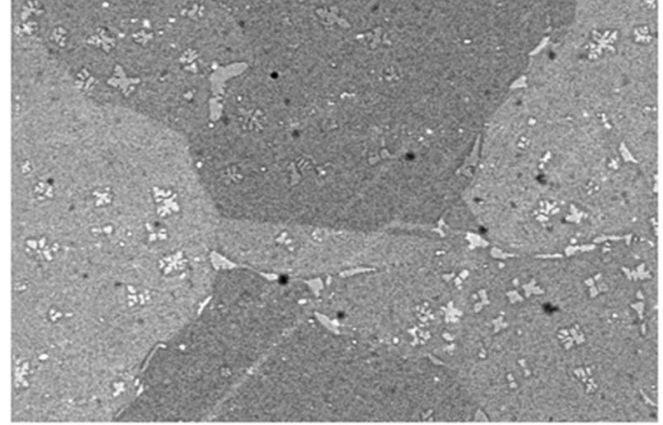

(b)

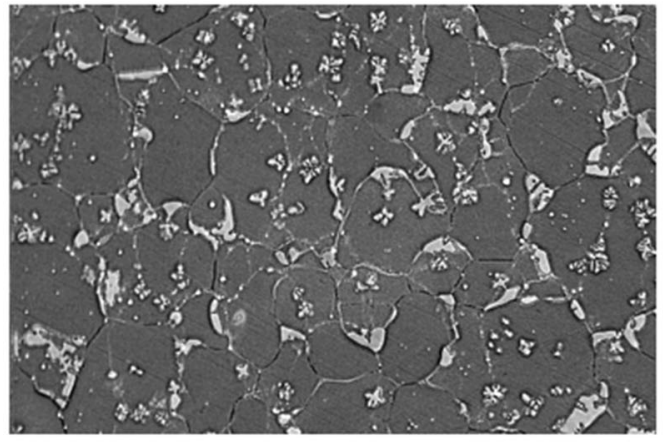

(d)

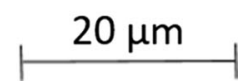

Fig. 12-Backscattered electron images from etched sections (etched with phosphoric acid) corresponding to $(a)$ as-HIP, $(b) \dot{\varepsilon}=0.1 \mathrm{~s}^{-1}$ deformed at $1413 \mathrm{~K}\left(1140{ }^{\circ} \mathrm{C}\right),(c) \dot{\varepsilon}=1 \mathrm{~s}^{-1},(d) \dot{\varepsilon}=10 \mathrm{~s}^{-1}$ deformed at $1373 \mathrm{~K}\left(1100{ }^{\circ} \mathrm{C}\right)$. Samples heated to $1443 \mathrm{~K}\left(1170{ }^{\circ} \mathrm{C}\right)$ and cooled to $1373 \mathrm{~K}$ $\left(1100{ }^{\circ} \mathrm{C}\right)$ at nominally $0.017 \mathrm{~K} \mathrm{~s}^{-1}\left(1 \mathrm{~K} \mathrm{~min}^{-1}\right)$ and water quenched.

conditions, $\mathrm{T}=1223 \mathrm{~K}$ to $1423 \mathrm{~K}$, strain rates $=0.1$ to $10 \mathrm{~s}^{-1}$, and true strains up to 0.9 . Furthermore, flow softening at typically, $\dot{\varepsilon}>1 \mathrm{~s}^{-1}$ is consistent with the flow stress behavior reported in low-stacking fault energy Ni-based alloys. ${ }^{[8,9]} \gamma$ grains that nucleate during DRX have different growth kinetics in case of $\dot{\varepsilon}=1$ and $10 \mathrm{~s}^{-1}$ resulting in the variation in grain size, Figures 5(a), (b) and 6(a), (b). The principal driving force in case of DRX arises from the remnant dislocation density into which the nucleated strain-free grain grows, while the retarding force is provided by the pinning of the grain boundary by the precipitates. The relative magnitude of these two forces will dictate the kinetics of grain growth.

Under condition of high strain rate/low temperature, i.e., akin to DRX, the variation of flow stress with dislocation density under high strain rate conditions is given by ${ }^{[24]}$

$$
\sigma=\alpha G b \sqrt{\rho},
$$

where $\sigma$ is the peak flow stress, $\alpha \sim 0.45$; $G$ is the shear modulus; $b$ is the Burgers vector; and $\rho$ the dislocation density. For $\dot{\varepsilon}=1$ and $10 \mathrm{~s}^{-1}, \sigma=325$ and $225 \mathrm{MPa}$, respectively, (Figure 1) and for RR 1000 at $1100{ }^{\circ} \mathrm{C}$, $G=46.2 \mathrm{GPa}, v=0.436, V_{\mathrm{m}}$ (molar volume) of $\gamma$ phase $=7.44 \times 10^{-6} \mathrm{~m}^{3}$ and $b=2.54 \times 10^{-10} \mathrm{~m}$. From Eq. [1], the dislocation densities are $\rho\left(\dot{\varepsilon}=1 \mathrm{~s}^{-1}\right)$ $\sim 1.82 \times 10^{15} \mathrm{~m}^{-2}$ and $\rho \quad\left(\dot{\varepsilon}=10 \mathrm{~s}^{-1}\right) \sim 3.79 \times 10^{15}$ $\mathrm{m}^{-2}$, which is $\times 10$ greater than that reported in
Reference 12 under comparable deformation conditions. The driving force is then given by ${ }^{[24]}$

$$
P_{\mathrm{d}}=\alpha G b^{2} \rho .
$$

Therefore, the driving force, $P_{\mathrm{d}} \quad\left(\dot{\varepsilon}=1 \mathrm{~s}^{-1}\right)$ $\sim 2.44 \times 10^{-12}{\mathrm{~J} \mu \mathrm{m}^{-3}}^{-3}$ and $P_{\mathrm{d}} \quad\left(\dot{\varepsilon}=10 \mathrm{~s}^{-1}\right)$

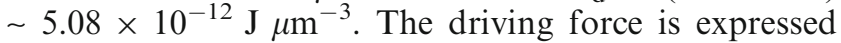
per unit volume, since it corresponds to the free energy per volume, which is released as the strain-free grains consume the strained matrix. However, it should be emphasized that the dislocation density can vary across grains, depending on whether the grain has most recently re-crystallized or not. Therefore, this estimate of the driving force is an average value.

The retarding force arises from pinning from the precipitates at the grain boundary. The inter/intragranular $\gamma^{\prime}$ precipitates in the as-HIP condition are coherent, as in Figure 4(f). Although adiabatic heating effects exist, as in Figures 2(a) and (b), the time for deformation, which is 1 and 0.1 seconds corresponding to strain rates of $\dot{\varepsilon}=1$ and $10 \mathrm{~s}^{-1}$, respectively, is insufficient for dissolution of $\gamma^{\prime}$ precipitates ${ }^{[25]}$ and a similar observation has been reported in Reference 12. The approach for calculation of the driving force and comments on the retarding force for DRX have similarities with that reported in Reference 12. The driving force in both cases has shown to be proportional to the dislocation density, which is calculated from the flow stress. The main difference arises in Eq. [1], where in the present case the 


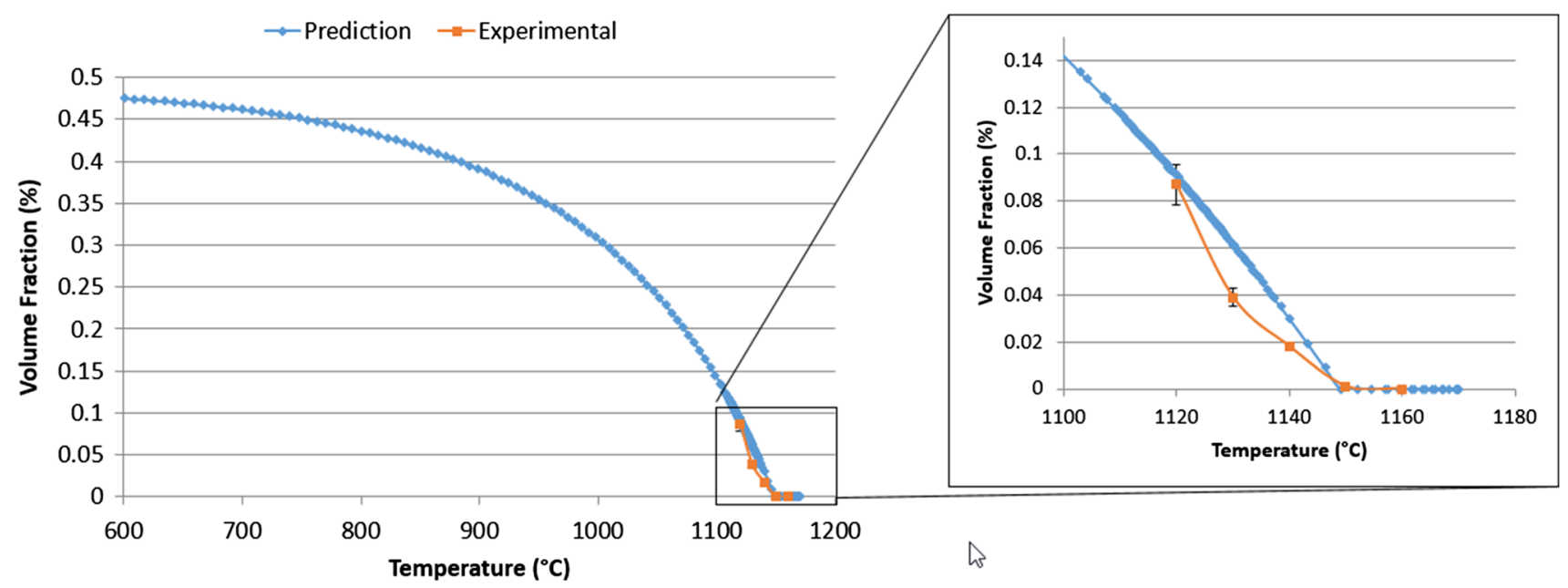

Fig. 13- Simulation of $\gamma^{\prime}$ volume fraction using mean-field precipitation kinetics during slow cooling from $1443 \mathrm{~K}$ to $873 \mathrm{~K}\left(1170{ }^{\circ} \mathrm{C}\right.$ to $600{ }^{\circ} \mathrm{C}$ ) at $0.017 \mathrm{~K} \mathrm{~s}^{-1}\left(1 \mathrm{~K} \mathrm{~min}^{-1}\right)$. Experimental data from Ref. [25] are included.

peak stress is considered, c.f., Figure 1. In Reference 12, however, a much lower flow stress of $50 \mathrm{MPa}$ was considered, which accounts for the lower dislocation density. A similar approach is adopted for the retarding force, which arises from the presence of incoherent inter/ intragranular primary precipitates, although unlike in Reference 12, no explicit calculations are made in this study.

\section{Mechanisms for formation of incoherent $\gamma^{\prime}$}

\section{precipitates}

The occurrence of incoherent inter/intragranular primary precipitates following hot compression at $1100{ }^{\circ} \mathrm{C}$ (sub-solvus) at strain rates, $\dot{\varepsilon}=1$ and $\dot{\varepsilon}=10 \mathrm{~s}^{-1}$ requires an explanation. Coherent precipitates interact with the grain boundary in three ways ${ }^{[26,27]}$ :

(a) The precipitate retains its coherency if dissolution of the precipitate occurs at the grain boundary. The solute supersaturation (Al, Ti) following dissolution results in precipitation of coherent precipitates within $\gamma$ matrix behind the boundary.

(b) When the boundary is pinned by the precipitate partial coherency loss occurs accompanied by a change in shape of the precipitate at the grain boundary. The increased particle radius subsequently results in capillarity-driven coarsening of the intergranular precipitate.

(c) Complete loss in coherency occurs when the grain boundary sweeps past the precipitate. If the initial coherent $\gamma^{\prime}$ precipitate lies in $\gamma$-grain 1 , then consumption of $\gamma$-grain 1 by $\gamma$-grain 2 through advancement of the grain boundary results in the $\gamma^{\prime}$ precipitate being incoherent with $\gamma$-grain 2 .

In case of (a), the rate of precipitate dissolution just ahead of the grain boundary should be sufficiently rapid and, able to keep pace with the mobility of the boundary. This has been reported in Reference 4, where the $\gamma$ grain re-crystallization front dissolves $\gamma^{\prime}$, which then precipitates discontinuously or continuously and coherently with $\gamma$ matrix phase. However, the predominant incoherent primary $\gamma^{\prime}$ precipitates for $\dot{\varepsilon}=1$ and $10 \mathrm{~s}^{-1}$ indicate that complete dissolution of coherent $\gamma^{\prime}$ precipitates ahead of the grain boundary does not occur. The existence of incoherent primary $\gamma^{\prime}$ precipitates suggests two possible mechanisms.

Mechanism (i) - The remnant plastic strain within the $\gamma$ matrix also provides a driving force for post-dynamic or meta-dynamic re-crystallization (MDRX) of $\gamma^{\prime}$ precipitates homogeneously or heterogeneously (intergranular) within $\gamma$ matrix. The nucleation and growth rates are given by the following expressions ${ }^{[28,29]}$ :

$$
\begin{gathered}
v=\frac{D \partial C_{\gamma} / \partial t}{\left(C_{\gamma^{\prime}}-C_{\gamma}\right)}, \\
\Delta G *=\frac{16 \pi \sigma^{3}}{3 \Delta G_{\mathrm{v}}^{2}},
\end{gathered}
$$$$
\dot{J}=N_{0} Z \beta \exp \left(\frac{-\Delta G *}{R T}\right) \exp \left(\frac{-\tau}{t}\right),
$$

where $N_{0}=$ density of active nucleation sites/volume (number $\mathrm{m}^{-3}$ ); $Z=$ Zeldovich non-equilibrium factor that corrects for the equilibrium concentration of critical nuclei for the loss of nuclei to growth (unitless); $\beta=$ rate of atomic attachment to the critical nuclei $\left(\mathrm{s}^{-1}\right) ; \Delta G^{*}$ is the activation energy for nucleation; $\sigma$ is the interfacial energy; $\Delta G_{\mathrm{v}}$ is the Gibbs volumetric free energy realized during nucleation of a precipitate phase; $C_{\gamma^{\prime}}$ and $C_{\gamma}$ is the elemental concentration in $\gamma^{\prime}$ and $\gamma$ at the $\gamma / \gamma^{\prime}$ interface; and $D=$ elemental diffusivity in $\gamma$ phase $\left(\mathrm{m}^{2} \mathrm{~s}^{-1}\right)$. Therefore, $\mathrm{J}$ has units of number $\mathrm{m}^{-3} \mathrm{~s}^{-1}$.

The number of active nucleation sites is dependent on the dislocation density and is given by ${ }^{[30]}$

$$
N_{0}=\rho\left(\frac{6.023 \times 10^{23}}{V_{\mathrm{m}}}\right)^{1 / 3},
$$


where $\rho$ is the dislocation density. Using $N_{0}$ and the remaining parameters in Eq. [3a] are from Reference 31 from which the nucleation rates can be calculated and given by

$$
\begin{aligned}
& \dot{\mathrm{J}}\left(\dot{\varepsilon}=1 \mathrm{~s}^{-1}\right) \sim 7.9 \times 10^{24} \text { nuclei } \mathrm{m}^{-3} \mathrm{~s}^{-1} \\
& \dot{\mathrm{J}}\left(\dot{\varepsilon}=10 \mathrm{~s}^{-1}\right) \sim 16.1 \times 10^{24} \text { nuclei } \mathrm{m}^{-3} \mathrm{~s}^{-1}
\end{aligned}
$$

The dislocation density can vary across grains, but importantly a large fraction has been consumed during DRX involving $\gamma$ grains. Therefore, this nucleation density is an upper bound, specifically when comparing with the simulations of slow continuous cooling in the case of the alloy UDIMET $720 \mathrm{Li}$, where $\mathbf{J} \sim\left(10^{14}\right.$ to $10^{16}$ ) nuclei $\mathrm{m}^{-3} \mathrm{~s}^{-1}$ for a typical cooling rate of $0.5 \mathrm{~K} \mathrm{~min}^{-1}$ from $1453 \mathrm{~K}\left(1180{ }^{\circ} \mathrm{C}\right) .{ }^{[28]}$ However, it must be pointed out that nucleation rate of $\gamma^{\prime}$ precipitates from Eq. [3a] does not distinguish between coherent precipitates and incoherent precipitates.

Nevertheless, the role of MDRX is expected to be more prevalent in case of $\dot{\varepsilon}=10 \mathrm{~s}^{-1}$, where the twofold increase in $\mathrm{P}_{\mathrm{d}}$ following from Eq. [2] provides the driving force for nucleation and growth of strain-free $\gamma^{\prime}$ precipitates. In case of $\dot{\varepsilon}=1 \mathrm{~s}^{-1}, \gamma^{\prime}$ precipitates predominantly nucleate on grain boundaries and therefore will be incoherent. However, sporadic instances of intergranular $\gamma^{\prime}$ precipitates are observed, but which are coherent with $\gamma$ matrix phase, as highlighted by white arrows in Figure 5(d). This indicates that these precipitates have nucleated homogeneously within the bulk, but a situation akin to (b) is observed, where the boundary that intersects the precipitate is pinned and some loss of coherency at the boundary will occur. The intergranular incoherent precipitates also are predominantly associated with a local average misorientation $<0.5 \mathrm{deg}$, as shown in Figure 5(e), thereby indicating strain-free $\gamma^{\prime}$ precipitates and occurrence of MDRX. In case of $\dot{\varepsilon}=10 \mathrm{~s}^{-1}$, the precipitates are predominantly intragranular, which points to another mechanism related to (c).

Mechanism (ii) - If the $\gamma^{\prime}$ precipitates cannot pin the grain boundary owing to large driving force, then the boundary will sweep past the precipitates. The driving force is consumed during grain growth and advancement of the boundaries will be retarded and the grain boundary will eventually be pinned. The Zener pinning force is given by ${ }^{[24]}$

$$
P_{\mathrm{z}}=\frac{3 f \sigma}{2 r},
$$

where $\sigma$ is the grain boundary energy, $f=$ volume fraction of precipitates, and $r=$ precipitate radius. It is not straightforward to use Eq. [5] for calculation of the pinning force, since there is a continuous growth of the precipitates during cooling with a progressive increase in both $\mathrm{f}$ as well as $\mathrm{r}$, which affects Eq. [5]. Further, the distribution of primary $\gamma^{\prime}$ precipitates on $\gamma$ grains are not random, with a distinct concentration at grain edges and corners. Nevertheless, as in the case of the driving force, the approximate pinning force in relation to the microstructure in Figure 5(d) can be made, where from image analysis, $f \sim 0.07$ and $r \sim 0.8 \mu \mathrm{m}$, average $\gamma$ grain size $\sim 1.46 \mu \mathrm{m}$ and $\sigma \sim 1 \mathrm{~J} \mathrm{~m}^{-2} \cdot{ }^{[12]}$ From Eq. [6], $\mathrm{P}_{\mathrm{Z}} \sim$ $0.13 \times 10^{-12} \mathrm{~J} \mu \mathrm{m}^{-3}$, which is 5 pct of the maximum driving force. In case of $\dot{\varepsilon}=10 \mathrm{~s}^{-1}$, owing to the twofold increase in driving force, the $\gamma$ grain boundaries initially breakaway from the primary $\gamma^{\prime}$ population, which explains the intragranular incoherent population. Only in the later stages, as in $\dot{\varepsilon}=1 \mathrm{~s}^{-1}$, the grain boundaries are pinned. Using Eq. [6] and for $f \sim 0.05$ and $r \sim 0.8 \mu \mathrm{m}$

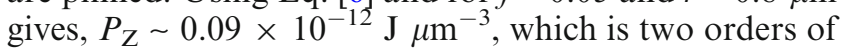
magnitude smaller than the driving force. The existence of a number of incoherent intragranular $\gamma^{\prime}$ precipitates, with local average misorientation $\sim 3 \mathrm{deg}$ (Figure 6(e)) is consistent with the homogenous nucleation of these $\gamma^{\prime}$ precipitates within the initially strained $\gamma$ grains. The subsequently strain-free nucleated $\gamma$ grains formed via DRX (local average misorientation $<0.5 \mathrm{deg}$, as in Figure 6(e)) and their high mobility results in incoherency of $\gamma^{\prime}$ precipitates when the grain boundaries sweep past these precipitates.

In lieu of mechanisms (i) and (ii), some comments must be made in relation to heteroepitaxial re-crystallization (HERX) reported in Reference 3, where the focus is on $\gamma$ grains, which nucleate as a thin rim of $\gamma$ phase on primary $\gamma^{\prime}$ precipitates. This is distinct to this study, since the focus here is on the incoherent $\gamma^{\prime}$ precipitates that form. HERX presupposes the existence of incoherent $\gamma^{\prime}$ precipitates to account for the subsequent re-crystallization of $\gamma$ grains during DRX. Also, HERX occurs for low strains, typically, $\varepsilon<0.6$, which is smaller than the strains in this study, c.f., Figures 3(a) and (b).

\section{B. Evolution of Gamma Prime Precipitates following Sub-solvus and Super-solvus Heat Treatment}

During isothermal hold at the sub-solvus temperature, $1373 \mathrm{~K}\left(1100{ }^{\circ} \mathrm{C}\right)$, coarsening of the precipitates occurs and consequently the precipitate fraction prior to quenching can be resolved in the electron images. This contrasts with continuous cooling, where the precipitates nucleated at close to the quenching temperature would not be resolved, owing to their smaller size. The hot-working conditions in this study are comparable with that reported in Reference 12, where when deformation was carried out close to solvus for strain rates $\geq 1 \mathrm{~s}^{-1}$ and during subsequent super-solvus heat treatment, uniform dissolution of primary intragranular $\gamma^{\prime}$ precipitates was observed. However, unlike in that study, in the present case sub-solvus heat treatment was carried out. Nevertheless, there exist sporadic undissolved incoherent precipitates, as in Figures 10 and 11, but complete dissolution at super-solvus conditions, as shown in Figures 12(c) and (d). The transformation of the incoherent primary $\gamma^{\prime}$ population to a predominantly coherent one arises from considerations of coarsening in the present experiments. For a binary system ( $\mathrm{B}$ is the solute) and a stoichiometric precipitate $(\beta)$, where the molar volume is independent of composition, the composition in the matrix phase at the $\alpha / \beta$ interface for a radius of curvature, $r$, and temperature (T) is given by ${ }^{[32]}$ 


$$
X_{\mathrm{B}}^{\alpha \beta}(r)=X_{\mathrm{B}}^{\alpha \beta}(r \rightarrow \infty)\left[1+2 \frac{\sigma V_{\mathrm{m}}^{\beta}}{r R T}\right],
$$

where $X_{\mathrm{B}}^{\alpha \beta}(r \rightarrow \infty)$ is the concentration in the matrix phase at the planar $\alpha / \beta$ interface; $\sigma$ is the surface tension; $V_{\mathrm{m}}^{\beta}$ is molar volume of $\beta$ phase. Classical theories have been developed to consider shape factors as well as anisotropy in interfacial energy in the dissolution kinetics of precipitates ${ }^{[33-35]}$ as well as the role of the initial particle size distribution. ${ }^{[36]} \mathrm{A}$ detailed analysis therefore will require size distribution of the initial incoherent and coherent precipitates. In case of the former, to some extent this can be obtained from image analysis of Figures 5(d) and 6(d), while the distribution of the coherent precipitates can be obtained from high-magnification views of Figures 5(c) and 6(c). However, it can be observed that the incoherent precipitates are irregular in shape and stereology plays a key role in coarsening and dissolution when anisotropy of surface energy exists. Therefore, a phenomenological approach is adopted to qualitatively address the dissolution of the incoherent precipitates. The driving force for coarsening arises from $\sigma / r$ in Eq. [6] and the rate of coarsening will be governed by the characteristic length. Owing to the irregular shape it is not straightforward to measure the radius of primary incoherent $\gamma^{\prime}$, but from Figures 4 through 6 , an average radius of $\sim 0.5 \mu \mathrm{m}$ can be reported. While for coherent precipitates $\sigma$ $\sim 0.02 \mathrm{~J} \mathrm{~m}^{-2[37]}$ in case of the incoherent ones, $\sigma$ $\sim 1 \mathrm{~J} \mathrm{~m}^{-2[12]}$ and therefore, $\sigma / r$ (incoherent) $\sim 2 \times 10^{6} \mathrm{~J} \mathrm{~m}^{-3}$. The size of coherent intragranular $\gamma^{\prime}$ is at least 20 times smaller, $\sim 0.025 \mu \mathrm{m}$ and $\sigma / r$ (coherent) $\sim 0.8 \times 10^{6} \mathrm{~J} \mathrm{~m}^{-3}$. Therefore, dissolution of the incoherent population will occur with a rate that is dependent on the initial particle size distribution. This is consistent with the observed intragranular precipitate distribution in Figures 8(b), 9(b), and 10(c) corresponding to $\dot{\varepsilon}=1 \mathrm{~s}^{-1}$ and Figures 8(d), 9(d), and 11(c) corresponding to $\dot{\varepsilon}=10 \mathrm{~s}^{-1}$. The precipitate fraction at the surface and center for $\dot{\varepsilon}=1 \mathrm{~s}^{-1}$ and at the surface for $10 \mathrm{~s}^{-1}$ are comparable, $\sim(0.11$ to 0.12$)$, but that at the center for $\dot{\varepsilon}=10 \mathrm{~s}^{-1}$ is greater by $\Delta V_{\mathrm{f}}\left(\gamma^{\prime}\right) \sim 0.04$. A possible explanation for the increased primary $\gamma^{\prime}$ fraction at the center for the higher strain rate suggests that a larger isothermal hold time $t>5400$ seconds $(90 \mathrm{~min}$ utes) is required for attaining the equilibrium fraction $\sim(0.11$ to 0.12$)$. However, the heat treatment experiments in Reference 25 report a typical annealing time of 1200 seconds (20 minutes), when an equilibrium fraction is reached. The role of strain in the evolution of the equilibrium precipitate fraction on heating to a given sub-solvus temperature therefore requires further investigation.

On the other hand, the role of remnant plastic strain in the evolution of the precipitate morphology can be more readily investigated using super-solvus conditions. At super-solvus temperatures all precipitates are dissolved and nucleate during subsequent cooling, where the observed inter/intragranular precipitates display two distinct morphologies, blocky intergranular and dendritic intragranular, Figures 12(a) through (d). However, unlike in isothermal sub-solvus heat treatment, during continuous cooling, precipitates nucleated near the quenching temperature will not be resolved metallographically and consequently it is not possible to reliably measure the total precipitate fraction at $1373 \mathrm{~K}$ $\left(1100{ }^{\circ} \mathrm{C}\right)$ prior to quench. Therefore, from the equilibrium precipitate fraction at $1373 \mathrm{~K}\left(1100^{\circ} \mathrm{C}\right)$, by subtracting the blocky intergranular and dendritic intragranular fraction in Section III-C-2, the fine intragranular secondary population can be calculated. In fact, such an approach in principle can be adopted at any temperature, by coupling image analysis on a quenched section with the equilibrium fraction computed at that given temperature. The first step is therefore calculation as a first approximation of the precipitate fraction at $1373 \mathrm{~K}\left(1100{ }^{\circ} \mathrm{C}\right)$ from a thermodynamic model. The precipitation kinetics simulation that was employed in this study is a mean-field formulation of the Svoboda et al. particle growth model in a super-saturated matrix ${ }^{[38]}$ which has been then adapted to use a fast-acting surrogate model for the phase Gibbs energy and the diffusivities and chemical potentials of the alloying elements $v s$ temperature. ${ }^{[39]}$ The model also considers the effect of misfit strain between the matrix and precipitate phase on the free energy of the system as well as a temperature-dependent interfacial energy. Previous studies on common powder alloys for disc rotor applications have established the initial value of this interfacial energy, ${ }^{[40]}$ and recent internal Single-Sensor Differential Thermal Analysis (SSDTA) data have been used to finely calibrate the model to match the onset and completion of precipitation. It should be noted that in the simulations only intragranular precipitates are considered and associated with a typical nucleation site density, $\sim 10^{28} \mathrm{~m}^{-3}$, compared with $\sim 10^{24} \mathrm{~m}^{-3}$ in case of primary $\gamma^{\prime}$ in Section IV-A. The evolution of the $\gamma^{\prime}$ population with temperature is presented in Figure 13, where nucleation occurs at 1398 $\mathrm{K}\left(1125^{\circ} \mathrm{C}\right)$ and the amount of $\gamma^{\prime}$ is 13.5 pct at $1373 \mathrm{~K}$ $\left(1100{ }^{\circ} \mathrm{C}\right)$. The subsequent secondary/tertiary populations on quenching constitute 23 and 9 pct, respectively (not shown in Figure 13), such that the overall $\gamma^{\prime}$ amount is 45.5 pct at room temperature. For completeness, the evolution of $\gamma^{\prime}$ is calculated up to $873 \mathrm{~K}$ $\left(600{ }^{\circ} \mathrm{C}\right)$, although it must be emphasized that the $\gamma^{\prime}$ fraction below $1373 \mathrm{~K}\left(1100{ }^{\circ} \mathrm{C}\right)$ contains both primary and secondary populations. Comparison is made with data reported in Reference 25, but importantly in the latter, the $\gamma^{\prime}$ fraction was measured in heating isothermal hold experiments, unlike in these simulations, which refer to cooling. Therefore, at $1373 \mathrm{~K}\left(1100{ }^{\circ} \mathrm{C}\right)$ as the total precipitate fraction is 0.135 , the volume fraction of the secondary population at the center is $(=0.135-$ measured volume fraction $)$ :

$$
\begin{aligned}
\text { As-Hip }-0.09(0.135-0.045) \\
\dot{\varepsilon}=0.1 \mathrm{~s}^{-1}-0.078(0.135-0.057) \\
\dot{\varepsilon}=1 \mathrm{~s}^{-1}-0.059(0.135-0.076) \\
\dot{\varepsilon}=10 \mathrm{~s}^{-1}-0.016(0.135-0.119) .
\end{aligned}
$$


There is a fivefold difference in the amount of the intragranular morphology, which reinforces the key role played by plastic strain in the evolution of the different precipitate morphologies. A systematic quantitative calculation of the role of plastic strain in the evolution of $\gamma^{\prime}$ can be done using calorimetry, where the samples from different deformation pedigrees can be heated to a super-solvus temperature and then cooled ${ }^{[41]}$ and the fraction calculated from enthalpy considerations or alternatively using detailed electron microscopy and atom probe tomography, ${ }^{[37]}$ but both these methods lie outside the scope of this study.

The key implication of this study is that the deformation conditions will determine the fraction of incoherent primary $\gamma^{\prime}$ precipitates, which in turn during subsequent heat treatment will play a key role in the evolution of the secondary intragranular coherent precipitates that are required for mechanical strength.

\section{CONCLUSIONS}

The objective of the current study was to investigate the microstructural evolution following compression and subsequent sub-solvus and super-solvus heat treatment in the Ni-based superalloy, R R1000. The following conclusions were made:

(1) Deformation was carried out on as-HIPped RR1000 under the following conditions: (a) $1373 \mathrm{~K}\left(1100{ }^{\circ} \mathrm{C}\right)$ to attain a final true strain, $\varepsilon$ $\sim 1$ for $\dot{\varepsilon}=1$ and $10 \mathrm{~s}^{-1}$ and (b) $1413 \mathrm{~K}\left(1140^{\circ} \mathrm{C}\right)$ to attain a final true strain, $\varepsilon \sim 1$ for $\dot{\varepsilon}=0.1 \mathrm{~s}^{-1}$ Subsequent cooling at $\sim 5 \mathrm{~K} \mathrm{~s}^{-1}$ following deformation.

(i) Recovery accompanied by stress decay, $\Delta \sigma$ $\sim$ [75 to 200] MPa occurs during forging, as well as dynamic re-crystallization (DRX) for $\dot{\varepsilon}=1$ and $10 \mathrm{~s}^{-1}$ resulting in re-crystallized strain-free $\gamma$ grains. This is more prominent for $\dot{\varepsilon}=10 \mathrm{~s}^{-1}$ associated with a higher driving force calculated from the dislocation density.

(ii) Primary $\gamma^{\prime}$ precipitates occur as intergranular for $\dot{\varepsilon}=1 \mathrm{~s}^{-1}$ and inter/intragranular for $\dot{\varepsilon}=10 \mathrm{~s}^{-1}$. In case of $\dot{\varepsilon}=1 \mathrm{~s}^{-1}$, meta-dynamic re-crystallization (MDRX) at grain boundaries results in the predominantly intergranular incoherent primary $\gamma^{\prime}$ population. In case of $\dot{\varepsilon}=10 \mathrm{~s}^{-1}$, the initial coherent nucleated/existing precipitates within $\gamma$ matrix become incoherent owing to their inability to dissolve just ahead of the advancing boundary or their inability to initially pin the boundary.

(2) Following sub-solvus isothermal heat treatment at $1373 \mathrm{~K}\left(1100{ }^{\circ} \mathrm{C}\right)$ for 90 minutes and water quenching:

(i) Precipitate coarsening occurs leading to the dissolution of the incoherent primary precipitates. The resulting precipitate population is predominantly coherent, though some sporadic incoherent precipitates exist.

(ii) There is a prominent intragranular $\gamma^{\prime}$ (coherent/incoherent) precipitate population for $\dot{\varepsilon}=10 \mathrm{~s}^{-1}$ and an increased precipitate fraction, $V_{\mathrm{f}}\left(\gamma^{\prime}\right) \sim 0.04$ compared with $\dot{\varepsilon}=1 \mathrm{~s}^{-1}$ at the center.

(3) Following heating up to super-solvus temperature, $1443 \mathrm{~K}\left(1170{ }^{\circ} \mathrm{C}\right)$ and then slow cooling at $0.017 \mathrm{~K} \mathrm{~s}^{-1}\left(1 \mathrm{~K} \mathrm{~min}^{-1}\right)$ to $1373 \mathrm{~K}\left(1100{ }^{\circ} \mathrm{C}\right)$ and water quenching:

(i) Two distinct coherent precipitate morphologies are observed, i.e., primarily blocky intergranular and dendritic intragranular, where the intergranular morphology becomes dominant with increasing strain.

(ii) Using numerical simulations, the role of strain in the evolution of the different precipitate morphologies was quantified. With increasing strain rate (strain), there is an increasing fraction of the blocky intergranular morphology and concomitant lower distribution of the second intragranular morphology.

\section{OPEN ACCESS}

This article is distributed under the terms of the Creative Commons Attribution 4.0 International License (http://creativecommons.org/licenses/by/4.0/), which permits unrestricted use, distribution, and reproduction in any medium, provided you give appropriate credit to the original author(s) and the source, provide a link to the Creative Commons license, and indicate if changes were made.

\section{REFERENCES}

1. I.M.D. Parr, T.J. Jackson, M.C. Hardy, D. Child, C. Argyrakis, K. Severs. V. Saraf, and J.M. Stumpf: in Proc. of the 13th Int. Symp. on Superalloys, Superalloys 2016, M.C. Hardy et al., eds., The Minerals Metals \& Materials Soc., pp. 447-56.

2. S.S. Satheesh Kumar, T. Raghu, P.P. Bhattacharjee, G. Appa Rao, and U. Borah: J. Alloy Compd., 2016, vol. 681, pp. 28-42.

3. M.-A. Charpagne, J.-M. Franchet, and N. Bozzolo: Mater. Des, 2018, vol. 144, pp. 353-60.

4. A. Seret, C. Moussa, M. Bernacki, and N. Bozzolo: Metall. Mater. Trans. A, 2018, vol. 49A, pp. 4199-4213.

5. H. Jiang, L. Yang, J. Dong, M. Zhang, and Z. Yao: Mater. Des, 2016, vol. 104, pp. 162-73.

6. Y. Wang, S.L. Zhen, L. Yang, and X.M. Zhang: Mater. Sci. Eng. A, 2008, vol. 497A, pp. 479-86.

7. A.A. Guimares and J.J. Jonas: Metall. Trans. A, 1981, vol. 12A, pp. $1655-66$.

8. J. Wang, J. Dong, M. Zhang, and X. Xie: Mater. Sci. Eng. A, 2013, vol. 566A, pp. 61-70.

9. D.-X. Wen, Y.C.X. Lin, H.-B. Li, X.-M. Chen, J. Deng, and L.-T. Li: Mater. Sci. Eng. A, 2014, vol. 591A, pp. 183-92. 
10. H. Zhang, K. Zhang, H. Zhou, Z. Lu, C. Zhao, and X. Yang: Mater. Des, 2015, vol. 80, pp. 51-62.

11. M.-A. Charpagne, T. Billot, J.-M. Franchet, and N. Bozzolo: J. Alloy Compd., 2016, vol. 688, pp. 685-94.

12. S.L. Semiatin, J.M. Shank, A.R. Shiveley, W.M. Saurber, E.F. Gaussa, and A.L. Pilchak: Metall. Mater. Trans. A, 2014, vol. $45 \mathrm{~A}$, pp. $6231-51$.

13. D.M. Collins, B.D. Conduit, H.J. Stone, M.C. Hardy, G.J. Conduit, and R.J. Mitchell: Acta Mater., 2013, vol. 61, pp. 3378-91.

14. M.S. Lewandowski and R.A. Overfelt: Acta Mater., 1999, vol. 47, pp. 4695-4710.

15. K. Huang and R.E. Loge: Mater. Des., 2016, vol. 111, pp. 578-74.

16. Y.Q. Chen, T.J.A. Slater, E.A. Lewis, E.M. Francis, M.G. Burke, M. Preuss, and S. Haigh: Ultramicroscopy, 2014, vol. 144, pp. 1-8.

17. A.R.P. Singh, S. Nag, S. Chattopadhyay, Y. Re, J. Tiley, G.B Viswanathan, H.L. Fraser, and R. Banerjee: Acta Mater., 2013, vol. 61, pp. 280-93.

18. C. Papadaki, W. Li, and A.M. Korsunsky: Materials, 2018, vol. 11 (152), p. 8.

19. Y.Q. Chen, E. Francis, J. Robson, M. Preuss, and S.J. Haigh: Acta Materialia, 2015, vol. 85, pp. 199-206.

20. S.J. Hessel, W. Voice, A.W. James, S.A. Blackham, C.J. Small, and M.R. Winstone: Nickel Alloy for Turbine Engine Component, US Patent 6132527, 2000

21. R.L. Goetz and S.L. Semiatin: J. Mater. Eng. Perform., 2001, vol. 10, pp. $710-17$.

22. W. Pantleon, D. Francke, and P. Klimanek: Comput. Mater. Sci., 1996, vol. 7, pp. 75-81.

23. DEFORM ${ }^{\circledR}$ is a registered trademark of Scientific Forming Technologies Corporation, 2545 Farmers Drive, Suite 200, Columbus, $\mathrm{OH}$.

24. F.J. Humphreys and M. Hatherley: Recrystallization and Related Phenomena. Elsevier Science Ltd., Oxford, 1996, Chapters 3 and 9.

25. D.M. Collins: PhD Thesis, University of Cambridge, UK, 2011.

26. A. Porter and B. Ralph: J. Mater. Sci., 1981, vol. 16, pp. 707-13.

27. V. Randle and B. Ralph: Acta Metall., 1986, vol. 34, pp. 891-98.
28. R. Radis, M. Schaffer, M. Albu, G. Kothleitner, P. Polt, and E. Kozechnik: Acta Mater., 2009, vol. 57, pp. 5739-47.

29. T.P. Gabb, D.G. Blackman, D.Y. Wei, D.P. Mourer, D. Furrer, A. Garg, and D.L. Ellis: in Proc. of the 9th Int. Symp. On Superalloys, Superalloys 2000, T.M. Pollock et al., eds., The Minerals Metals and Materials Soc., 2000, pp. 405-14.

30. J.W. Cahn: Acta Metall., 1956, vol. 4, pp. 572-75.

31. Thermo-Calc 2016a, TCNI8/MOBNI4, Thermo-Calc Software $\mathrm{AB}$, Råsundavägen 18, 16967 Solna, Sweden.

32. D. Porter and K. Easterling: Phase Transformations in Metals and Alloys, 2nd eds, CRC Press, Boca Raton, 1992.

33. K. Kim and P.W. Voorhees: Acta Mater., 2018, vol. 152, pp. 327-37.

34. E. Kozeschnik and J. Svoboda: Mater. Sci. Eng. A, 2006, vol. 441, pp. $68-72$.

35. J. Svoboda, F.D. Fischer, P. Fraftzl, and E. Kozeschnik: Mater. Sci. Eng. A, 2004, vol. 385, pp. 166-74.

36. M. Perez, M. Dumont, and D. Acevedo-Reyes: Acta Materialia, 2008, vol. 56, pp. 2119-32.

37. S.S. Babu, M.K. Miller, J.M. Vitek, and S.A. David: Acta Mater., 2013, vol. 61, pp. 280-93.

38. J. Svoboda, F.D. Fischer, P. Fratzl, and E. Kozeschnik: Mater. Sci. Eng. A, 2004, vol. 385 (1-2), pp. 166-74.

39. M.J. Anderson, C. Panwisawas, Y. Sovani, R.P. Turner, J.W. Brooks, and H.C. Basoalto: Acta Mater., 2018, vol. 156, pp. $432-45$.

40. G.B. Olson, H.-J. Jou, J. Jung, J.T. Sebastian, A. Misra, I. Locci and D. Hull: in Proc. of the 11th Int. Symp. on Superalloys, Superalloys 2008, The Minerals Metals and Materials Society, 2008, pp. 923-32.

41. F. Masoumi, D. Shahriari, M. Jahazi, J. Cormier, and A. Devaux: Sci. Rep., 2016, vol. 6, p. 28650.

Publisher's Note Springer Nature remains neutral with regard to jurisdictional claims in published maps and institutional affiliations. 